\title{
Investigating Approaches of Integrating BIM, IoT, and Facility Management for Renovating Existing Buildings: A Review
}

\author{
Abubaker Basheer Abdalwhab Altohami *, Nuzul Azam Haron, Aidi Hizami Ales@Alias and Teik Hua Law \\ Department of Civil Engineering, Faculty of Engendering, University Putra Malaysia, Serdang, \\ Selangor 43400, Malaysia; nuzul@upm.edu.my (N.A.H.); aidihizami@upm.edu.my (A.H.A.); \\ lawteik@upm.edu.my (T.H.L.) \\ * Correspondence: gs50517@student.upm.edu.my
}

check for

updates

Citation: Altohami, A.B.A.; Haron, N.A.; Ales@Alias, A.H.; Law, T.H. Investigating Approaches of Integrating BIM, IoT, and Facility Management for Renovating Existing Buildings: A Review. Sustainability 2021, 13, 3930. https://doi.org/ $10.3390 /$ su13073930

Academic Editor:

Antonio Garcia-Martinez

Received: 6 February 2021

Accepted: 2 March 2021

Published: 2 April 2021

Publisher's Note: MDPI stays neutral with regard to jurisdictional claims in published maps and institutional affiliations.

Copyright: (c) 2021 by the authors. Licensee MDPI, Basel, Switzerland. This article is an open access article distributed under the terms and conditions of the Creative Commons Attribution (CC BY) license (https:// creativecommons.org/licenses/by/ $4.0 /)$.

\begin{abstract}
The importance of building information is highly attached to the ability of conventional storing to provide professional analysis. The Internet of Things (IoT) and smart devices offer a vast amount of live data stored in heterogeneous repositories, and hence the need for smart methodologies to facilitate IoT-BIM integration is very crucial. The first step to better integrating IoT and Building Information Modeling (BIM) can be performed by implementing the Service-Oriented-Architecture (SOA) to combining software and other services by replacing the sematic information that was failed to display elements of indoor conditions. The other development is to create link that able to update static models towards real-time models using SOA approach. The existing approach relies on one-way interaction; however, developing two-way communication to mimic human cognitive has become very crucial. The high-tech approach requires highly involving Cloud computations to better connect IoT devices throughout Internet infrastructure. This approach is based on the integration of Building Information Modeling (BIM) with real-time data from IoT devices aiming at improving construction and operational efficiencies and to provide high-fidelity BIM models for numerous applications. The paper discusses challenges, limitations, and barriers that face BIM-IoT integration and simultaneously solves interoperability issues and Cloud computing. The paper provides a comprehensive review that explores and identifies common emerging areas of application and common design patterns of the traditional BIM-IoT integration followed by devising better methodologies to integrate IoT in BIM.
\end{abstract}

Keywords: BIM; IoT; integration BIM-IoT; creating database; live data

\section{Introduction}

In the last three decades, a new field in construction and design has been evolving with a revolutionary approach called Building Information Modelling (BIM). BIM is defined by [1] as "a model-based process of generating and managing coordinated and consistent building data that facilitates the accomplishment of established sustainability goals." This definition means that BIM has reached a level to facilitate high-level analysis and evaluations for building by employing techniques such as acoustic analysis, carbon emission, construction and demolition waste management, operational energy use, and water use. In addition, BIM of multidisciplinary data for various analyses could be expressed in a 3D model [2].

BIM takes full consideration of the environmental issues in terms of increasing demand for new and renovating buildings especially in the field of the high-quality indoor environment that has impacted the designing and construction of building. Further, BIM could cover the old buildings by keeping them in a good shape and environmentally suitable for living [3].

The existing building practitioners are facing a series of challenges such as the unavailability of BIM records-the matter that causes very poor assessment and lesser accuracy [3]. 
Therefore, existing buildings, using BIM technology, can be very productive when renovators are using 3D modeling, information management, and other information gathered from owners or tenants [4]. The other factor of the BIM success is that BIM is a data-rich, intelligent, and object-oriented parametric building modeling tool [5]. It can feed information of various categories into a 3D model. Additionally, BIM innovative development could provide opportunities to support green buildings via employing high-tech programs or devices such as the Internet of Things (IoT) and smart devices. These devices produce high quality live data about the building. The gathered information from different sources can be stored in heterogeneous repositories [6]. Based on the definition of IoT which emphasizes the nature of interconnection of sensing and actuating devices, the ability to share information through a unified framework could develop a common operating picture for enabling innovative applications [7]. The critical importance of IoT lies in allowing sensitive technologies such as sensing, identification, and recognition run by advanced hardware, software, and cloud platforms to draw better sense for how to deal correctly with the renovation and/or demolishing [8]. IoT is an architecture that uses intelligent devices, smart mobile devices, single board computers, different types of sensors and actuators [9].

The facility management industry may be a source of information; however, this information is invaluable in the sense of providing and delivering a timely and professional analysis in addition to the level of consultation support for more effective management services. The integration of information may provide value despite existing barriers and considerations upon combining the managerial building information with the live data [6]. At this point, considering these barriers may stand for a potential approach that supports integrating information and live data academically and industrially [6]. For these reasons, a comprehensive review of emerging areas of application and common design patterns to tackle BIM-IoT device integration in addition to examining the current limitations and predictions [10]. BIM-IoT integration is still in the early stages, which needs serious efforts to achieve a better understanding of the current situation [10]. The benefit for the real-time integration of the environmental and localization data could help in operational construction and facility management by applying the cloud-based BIM platform in the construction and facility management and operation vis two case studies [11].

The combination of IoT and the Lean and Injury-Free (LIFE) construction management may conceptualize the implementation of the topics in existing systems to designing and creating a valid prototypical application in field-typical work settings [11]. Keep in mind that BIM has been relying on data includes building characterization information which is very important in offering information on previous stages of the building's life cycle. The life cycle can be shown through plans either in paper version or digital drawing (Auto CAD), reports, tables, and others. As reported recently by [6], BIM technology could be available in a better platform than thought to be.

The basic rule of BIM in existing buildings relies on delivering or providing information that retrieved from any source that describes the conditions of these buildings or original data. In either case, informative data could be used towards evaluating the renovation process. However, the benefit of this information could be more valuable upon integrating this information in BIM. There are two reasons for this approach: the first reason is that this information came from different sources with a different format, and the second reason, BIM upon integrating data, can organize and prepare them under certain usable format. As an example, a laser scanning cloud provides good information, but it lacks semantic information or geometrical context which makes BIM searching for external sources such as building specification and construction materials. At the time of the laser scanning, data are useful for high-resolution images for spectral and spatial information [12]. The bottom line is the interoperable software programs and database contents of BIM that are featuring the better usage or application of the available information [13].

The above approach can be seen in Figure 1 which shows two parallel applications of BIM: one for new construction while the second is for existing buildings. For new buildings, 
the BIM process over the life cycle (LC) consists of inception, brief, design to production (case I) followed by maintenance and deconstruction (case II). In case that Architecture, Engineering, and Construction (AEC)/facility management (FM) stakeholders do not employ all BIM processes, an isolated BIM is then created for certain designated single purposes. BIM processes in existing buildings depend on the availability of pre-existing BIM (case II) [14] or created a new IM process procedure (case III). Buildings information for existing buildings is not available in BIM formats, and hence a case study has been proposed to produce 3D CAD models of existing structures using a semi-automated technique $[15,16]$. Hence, the only way to implement BIM is to utilize manual reverse engineering processes which is costly and time-consuming (case III) [17].
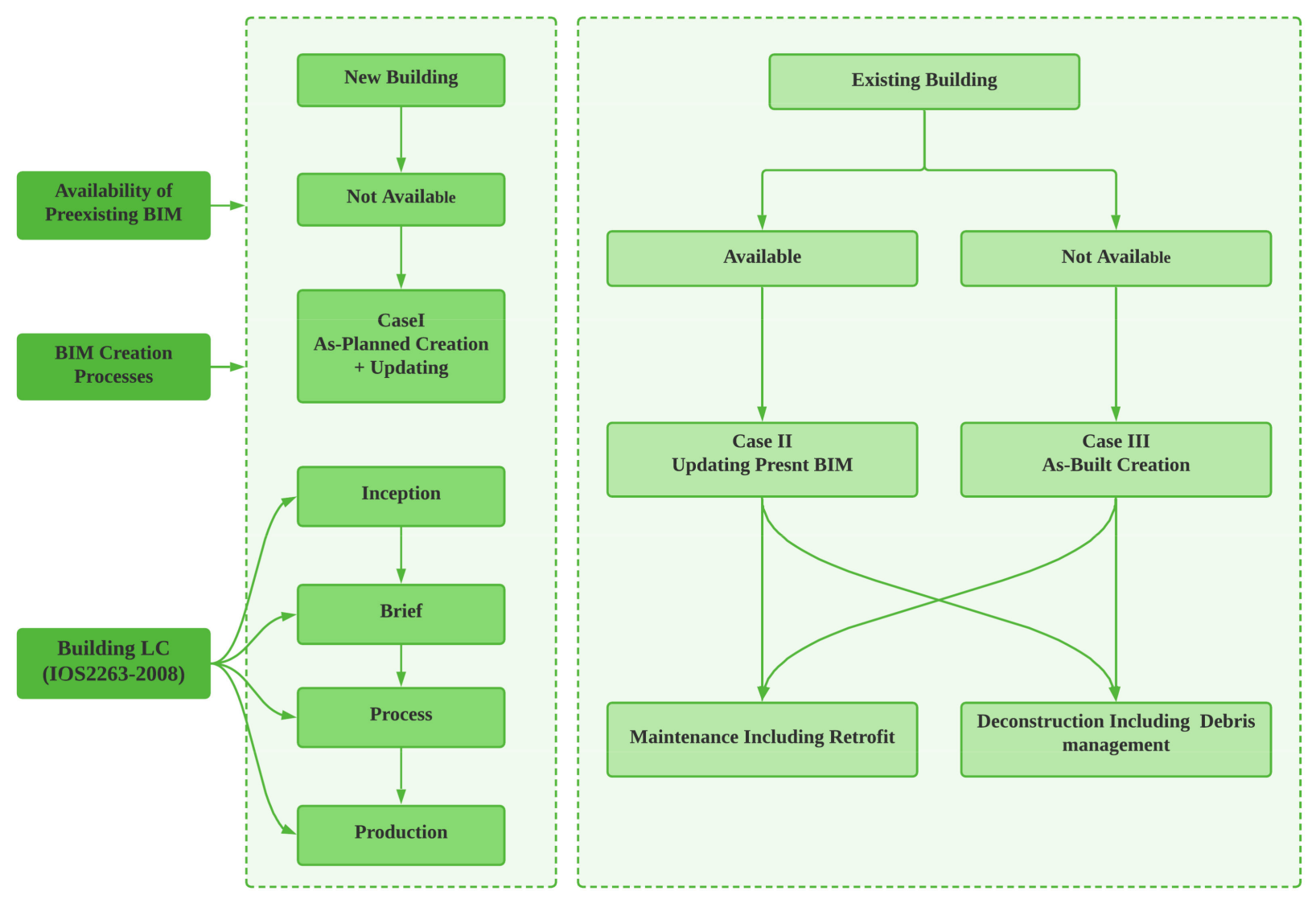

Figure 1. Building Information Modeling (BIM) model creation processes in new or existing buildings depending on available, pre-existing BIM and life cycle (LC) stages with their related requirements [18].

The important step is to utilize information obtained from the high-tech apparatus in the databases of ASCE, IEEE, ACM, and Elsevier Science Direct Digital Library. Meanwhile, the analytical data applied in the construction industry could be saved in the system of Big Data technologies at a very early stage [19]. A collection and relevant analysis of 614 bibliographic records from the science Web database have shown that BIM is mainly developed and applied in the USA, South Korea, and China [20]. Table 1 shows an indepth analysis of the reviewed papers on the four domains where BIM and IoT were operated. These four domains are operation and monitoring, logistic and management, facility management, and health and safety.

The paper is structured to contain nine sections include the Introduction. In Section 2, this paper discusses the relationship between BIM and the existing building. A discussion for integrating BIM and IoT are discussed in Section 3. Section 4 highlights implementing the big-data principles in integrating BIM and IoT. Section 5 illustrates the approaches to integrating BIM-IoT devices. Section 6 explains the query language. Section 7 contains a 
summary of previous empirical research. Section 8 highlights the contribution of this study, while Section 9 displays the conclusion.

Table 1. Recent studies on BIM-Internet of Things (IoT) implementation in existing buildings [10].

\begin{tabular}{cc}
\hline Construction Type & Reference \\
\hline Operation and Monitoring & {$[21-23]$} \\
Logistic and Management & {$[24-27]$} \\
Facility Management & {$[28-31]$} \\
Health and Safety & {$[23-32]$} \\
\hline
\end{tabular}

\section{BIM and Existing Buildings}

It is crucial to outline the flow of the topics in this paper as described in the flow diagram shown in Figure 2. One of the purposes of this flow diagram is to assist the authors in viewing the proposed system in a structured fashion.

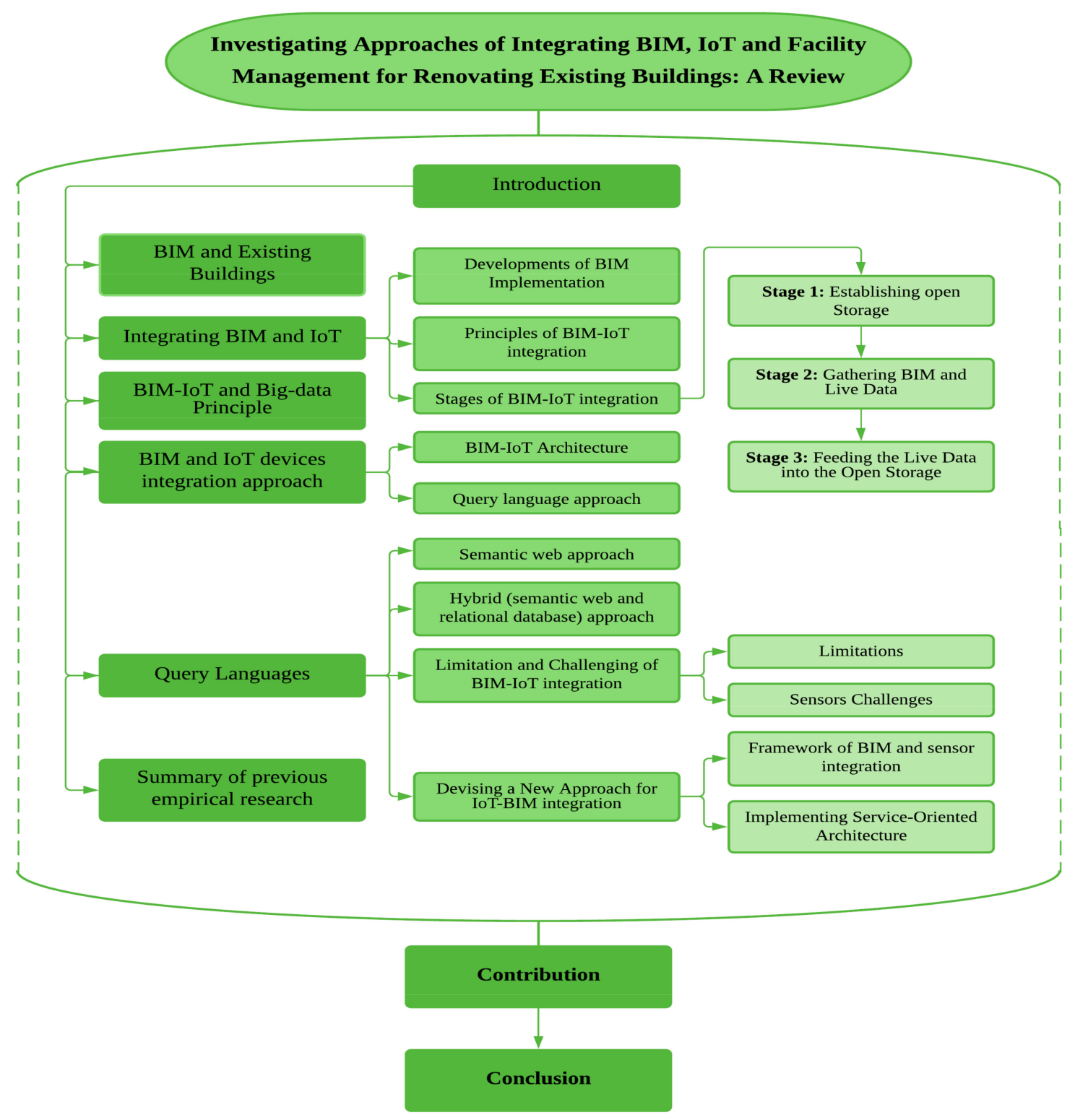

Figure 2. The methodology diagram flowchart. 
As stated by [33] that BIM is a new digital and management paradigm that shows great potential for renovating buildings despite critical issues such as missing documentation. Within this concept, the role of BIM is to facilitate the connection with stakeholders including the facility management to collect discontinued or unavailable information towards establishing a database. For this reason, BIM has become increasingly attractive to the management that deals normally with comprehensive and incremental knowledge for accurate assessment of recovering the residual building performances throughout refurbishment and retrofit [34]. This approach has become possible by extending the effective involvement of all technicians who are equipped with multidisciplinary skills besides sharing successful information [35]. The most important step is to integrate BIM and automation systems, which could positively support the quality control throughout diagnosis, design, work execution, and labor savings. Hence, BIM is characterized as a guide tool that controls the flow of work and information and stands on integrating digital archive of geometric, semantic, and topological data, which can be performed in various formats and contents within parametric objects [36]. The customized tools of BIM can manage and examine the variable multiplicity due to query operations and specifically programmed automation algorithms [37].

The involvement of BIM in heritage buildings, as a part of existing buildings, was initially identified as Historic Building Information Modelling (HBIM) [38]. Since then, HBIM has been adopted by many researchers [39]. The previous definition of BIM excludes information management. However, including this information in later BIM definition made an evolution in terms of approaching the Built Heritage Information Modelling and Management (BHIMM) [40].

The existence of state-of-the-art in BHIMM for building refurbishment whether in general terms [41] or for existing buildings [42] has made a very important step towards integrating BIM with other tools. Despite that, more guidelines are still needed to achieve a complete "as-built" model featured with morphology (regular or irregular) of historical buildings hoping to finalize an accepted design of refurbishment and conservation interventions as noted earlier by [43] and recently by [44]. Meanwhile, researchers face a critical activity when BIM and a variety of information through independent and structured methods. Such information can be gathered from various sources such as historically archived documentation and analytical investigations in addition to taking surveys, diagnostics, monitoring, and continuous updating information during designing, execution, or performance assessment [39]. HBIMM can be used successfully in improving BIM ability to include tangible and intangible information for the existing buildings, in general, as reported earlier by [45] and later by [39]. This information could be available to managerial and maintenance stakeholders throughout the life cycle. Further, fortifying this information with real-time updates may help to centralize models by installing integrated monitoring systems $[46,47]$. The state-of-the-art was drawn up to achieve the following four purposes: a critical analysis of potentialities of HBIMM, formalizing the first attempts of HBIMM application, proposing a consolidated methodological flow, and suggesting diagnosis tools for future developments within an automation-based framework.

\section{Integrating BIM and IoT}

Reference [48] defined data integration as "the combination of data from different sources with unified access to the data for its users". To achieve the goal of data integration, many researchers have proposed methods and models. However, integrating data in this study is limited to integrate the building information with the live data to achieve better facilitation to the maintenance of the buildings. It is important to note that the result of data integration so far is showing inadequate processes because of challenges faced by BIM and other building information management technologies as reported recently by $[49,50]$. In this section, a description of the foundations of data integration is presented, followed by explaining the challenges and barriers, and finally, the three stages necessary to achieve BIM and IoT integration. 


\subsection{Developments of BIM Implementation}

Generally, modification, altering, developing a new concept must come with a reason. Integrating IoT in BIM can be seen through the progressive developments of BIM as influential technology despite the appearance of some shortcomings or barriers [51]. BIM historically has become the core of information management in the Architecture, Engineering, and Construction (AEC) industry, operation, and maintenance (O\&M), and facility management (FM) [52]. Another benefit of emerging BIM is that it allows stakeholders to exchange and manage information about building throughout the building lifecycle as early reported by [53] and then by [54]. In addition, it has been reported that BIM could become an influential tool for analyzing energy usage, defect detection, firefighting, renovation and demolition, and safety in the facility [55]. Among these areas, the adoption of BIM in the AEC industry was very well established, whereas BIM has received growing attention for O\&M and FM [30]. The implementation of BIM in Architecture, Engineering, Construction, and Operation (AECO) was limited to include only new projects [56].

It is a fact that BIM was created to be applied heavily in new construction projects; however, there is another parallel movement to utilize BIM in existing buildings where BIM has not existed [57]. The sematic approach could rich the creation of BIM to face challenging, complex, and expensive considering [57]. In addition, generating BIM has become complex since it relies on the level of detail (LoD), intended use, interoperability, and functional issues [58]. Accordingly, implementing BIM for the existing building has yet to be fully realized.

In construction, it is a well-known fact that the O\&M period is the longest in the building lifecycle. In this period, all buildings require a monetary expense for labor, materials, maintenance, and renovation that makes this period the costliest [59]. It was reported by [60] that $85 \%$ of the total project cost is spent on O\&M activities. Meanwhile, O\&M information is not accurate and can be described as fragmented due to manual and tedious reporting method. The following barriers hinder attaining an effective O\&M:

- Under scientific and technological developments, building systems have become increasingly complex due to utilizing sophisticated technologies, security issues, and sustainability [61,62].

- Maintenance and repair of the life cycle of O\&M and FM result in injuries caused by falling, electric shocks, crushing, and other workers and facility users.

- Retrofitting existing buildings poses a great technical challenge such as energy interaction of the audit system, building performance and risk assessment, and energy savings $[63,64]$.

- According to [65] and recently to [66], a large portion of total energy worldwide has been spent on the current operations of the existing building. Hence, utilizing energy efficiently is indeed a prime concern in reducing stress on the energy system and benefits the environment. In this sense, BIM can significantly improve energy analysis through simulation [67].

- The fragmented O\&M causes energy simulation very difficult leading to a possible error-prone decision in the renovation along with issues such as safety, repair, and maintenance [68].

According to the above analysis, the more and accurate O\&M information the best outcome for the building's lifecycle. Hence, BIM, digital environment, and 3D visualization capabilities, enabling storage, sharing, and integration of information are essential for all stages in the renovation of existing buildings [69]. The successful implantation of BIM during design and construction using the digital database is very necessary for management and stakeholders. However, it is very important to note that using the same BIM in O\&M and FM could cause limited inconsistencies and the possible absence of the uncounted number of information necessary for O\&M and FM [70].

Moreover, like advanced technology, the Construction Operations Building Information Exchange (COBie) was created to eliminate the interoperability issues between the 
model and construction operated by FM [46]. Briefly, BIM integrated into O\&M and FM for the existing building still needs updating.

\subsection{Principles of BIM-IoT Integration}

Technology has been found very useful in enriching BIM with information that helps in adopting renovating existing buildings, such as 2D floorplans and elevation drawings. 2D can semantically enrich BIMs with proper and useful geometry for energy simulation for daily operations in addition to flexible building information from the facility management to formulate an informative model approach [71]. The input/output (IO) data has been utilized to quantify the embodied energy intensity of residential and commercial sectors in the USA [72]. In another approach, the optimization of the multi-objective algorithm could be implemented to improve the building stock energy efficiency, sustainability, and comfort, while efficiently allocating the available budget to the buildings [73].

This process requires expert knowledge to handle the core steps to deal with challenges that occurred in handling occlusions/uncertain data. In this case, the conversion process has become cumbersome as BIM data increased to a level of detail (LoD) which, then, requires using different techniques to capture imaging, 3D scanner, Ground Penetration Radar (GPR), and 2D scanned plans [52]. The missing BIM of most existing buildings adds restrictions for constructing BIM using high-tech devices.

On the other side, employing a BIM-based Data Mining (DM) approach for detecting improper records may lead to construct a BIM database. This is an introductory step towards transferring the database into a data warehouse where the DM method shows useful information from the BIM [74]. The BIM-oriented approach produces 3D models based on gathering data for geometrical and non-geometrical information related to various several themes.

These themes include historical documents to monitor other data that was created by reflecting the shared parameters for the ontology domain. The result of this approach is structuring data in a machine-readable format by converting needed data and set this data in a domain [75].

\subsection{Stages of BIM-IoT Integration}

The integration of BIM and IoT devices has been widely considered as a powerful paradigm processing aiming at improving construction and operational efficiencies. This integration is meant to serve the rapid expansion of IoT sensor networks and to cope up with these developments to achieve establishing high-fidelity BIM models that, ultimately, provide numerous applications. There are two important issues about BIM-IoT integration. The first issue is that this integration is still in its early stage. The second issue is that there is more than one approach for this integration depending on the reason and the limitation of such integration [10].

In one of the several BIM-IoT integration methods, utilizing the existing BIM tools' Application Programming Interface (APIs) and relational database was adopted as shown in Figure 3. This integration requires storing the time-series data from sensor time-series data stored and update it in a relational database in forms such as SQL server database or Microsoft Access. In addition, exporting BIM models constructed in BIM tools such as Revit into a relational database. The next step is to define a database schema to clarify the relationship between virtual objects and physical sensors. It is important to highlight that such integration requires a two-way importing and exporting of a relational database and BIM model. Lastly, BIM-IoT integration should process queries of sensor data through custom-built API in the form of the graphic user interface (GUI) and direct query over SQL database [10]. 


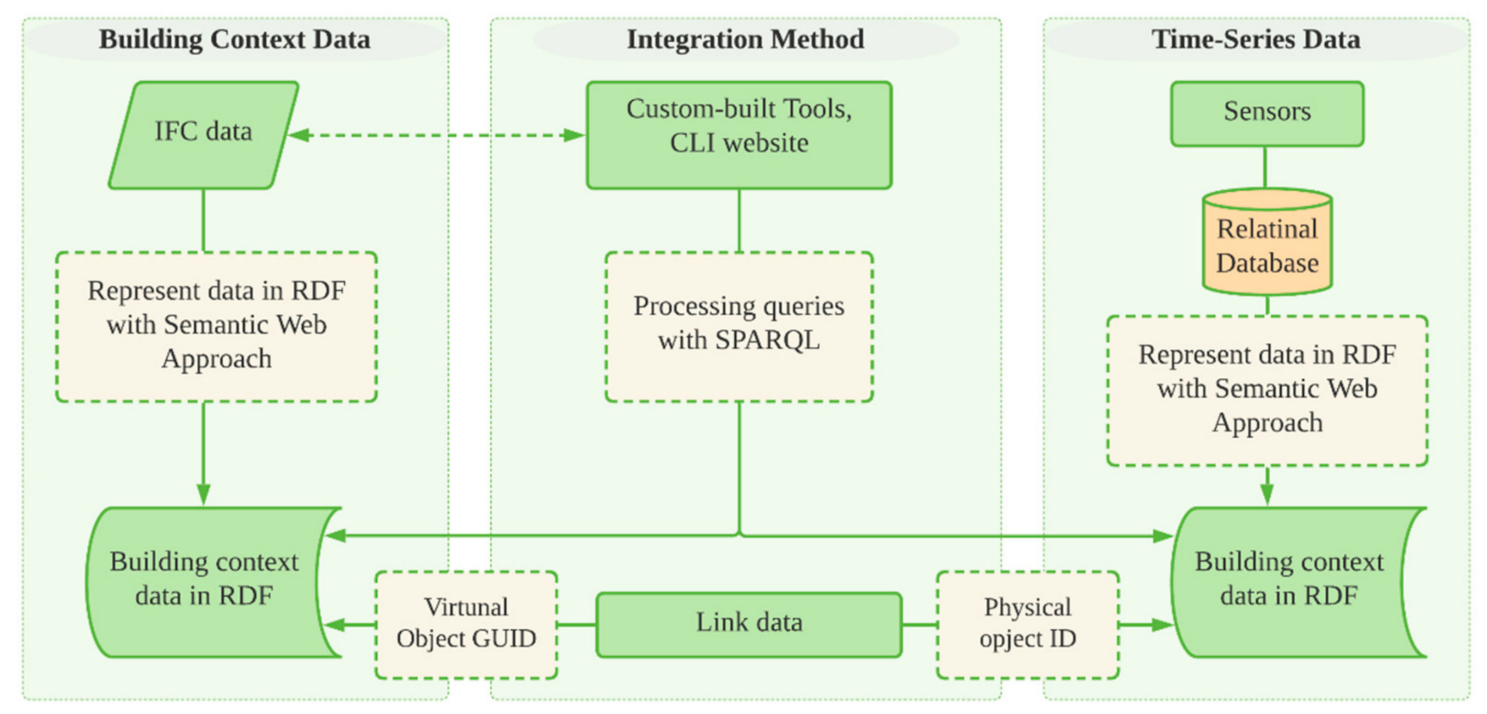

Figure 3. Integration of BIM tools and the relational database [10].

As mentioned above, BIM and IoT integration can be performed differently using a systematic method throughout three stages. The foundation of this systematic integration was based on the challenges that are facing BIM-IoT integration. It seems that tackling these challenges cannot be performed directly; seemingly, it needs a detailed process with definite stages. This approach suggests collection, analyzing, building information with the live data captured from various IoT and smart devices and sensors. The proposed process includes three stages explained as follows:

\subsubsection{Stage 1: Establishing Open Storage}

The first stage of the proposed process model is to facilitate storage in which the integrated, qualified building information, and live data are stored according to the construction industry standards such as ISO 16739, ISO 12006, ISO 29481, and, in some cases, the European standards for the construction industry. These standards require structural and semantic requirements with specific data systems. In this regard, the data storage should bed initially structured and well defined [76]. The final structure of the open storage could be completed after having the following two stages completed and assessed.

\subsubsection{Stage 2: Gathering BIM and Live Data}

Stage Two includes proposing various sub-processes aiming at capturing the building information and the live data from various sources such as reports and IoT devices and sensors. Firstly, digitalizing the building information taken from sources such as architectural, mechanical, electrical plans as well as the project reports. It is expected that building plans contain important and basic information about the buildings in terms of spaces and specific devices. In addition, there is another source of information that comes from mechanical development, electrical design and consumption, and structural systems. At this level, the basic information required is gathered and ready for the digitalizing process. As a connection to the coming sub-stage process, the digitalized data and information should be linked to the plans and the project reports [76].

The Stage Two-second sub-process includes detecting all installed IoT devices and sensors in the building by updating the information of these devices. The detection is normally carried out by laser scans followed by capturing images and video records. The outcome then develops a list of devices in cloud data forms and converts them to objects. Stage two could benefit from the data stored according to the previous Stage one. At the end of Stage two, it is important to note iterative processes of feeding the live data into the storage is explained in the following Stage Three. 


\subsubsection{Stage 3: Feeding the Live Data into the Open Storage}

Stage Three is the last stage where the proposed process model will be transferred into qualified live data for storage. Collectively, captured data from the IoT and smart devices must be stored according to the software of the databases. This critical step requires a well-defined interface that enables transferring data to the storage. The issue of live data mentioned earlier in Stage 2, the installation is carried out concurrently with the installed devices in the building spaces which can be transferred to the corresponding fields in the storage. In all stages, the quality of the stored data should pass the control test before getting ready for use [76].

\section{BIM-IoT and Big-Data Principle}

A big database is one of the perquisites of the digital revolution [77]. There are several sources of the big database with diverse disciplines including initiation, modeling, engineering drawings, and the facility life cycle. In addition, BIM has been proposed to involve the technology that captures multi-dimensional CAD information supporting multidisciplinary stakeholders [23,78]. The BIM data encodes 3D geometrical, computed intensively with graphic and Boolean computing, compressed in various formats, and intertwined [79]. Seemingly, the diverse data within BIM models gradually continued beyond the end of the facility. For example, the size of the BIM files with designing a three-story building could hit 50 GB [80]. This data can be in any form or shape and constitutes an intrinsic value to industrial performance. The evolution of the advent of embedded devices and sensors was a good approach to facilitate and generate massive data during the operational and maintenance stage leading to the creation of a Big BIM Data system [81]. Consequently, the vast accumulation of the BIM data has pushed the construction industry to enter the Big Data era. Big Data is characterized by three attributes that are commonly known as 3V's. These three V's are the volume (terabytes or petabytes); the variety (heterogeneous formats like text, sensors, audio, video, graphs, and more); and the velocity (continuous streams of the data) [82]. The formats of the construction data include DWG (drawing), DXF (drawing exchange format), DGN (Design), RVT (Revit), ifcXML (Industry Foundation Classes XML), ifcOWL (Industry Foundation Classes OWL), DOC/XLS/PPT (Microsoft format), RM/MPG (video format), and JPEG (image format). Additionally, the nature of construction data is natural dynamics due to the streaming properties of data sources such as sensors, Radio Frequency Identifications (RFIDs), and BMS (Building Management System).

At this level of understanding, it is important to remove ambiguity between Big Data Engineering (BDE) and Big Data Analytics (BDA). Firstly, the BDE domain presents the need for analysis of the data storage and processing activities. In addition, Big Data Analytics (BDA) relates to the tasks responsible for extracting the knowledge to drive decision-making $[83,84]$. According to [85], the nature of BDA is to discover the latent patterns that is buried inside Big Data. As such, it becomes plausible to transform the future of many industries through data-driven decision-making. For future expectations, identifying, understanding, and reacting to the latent trends promptly could show a competitive edge in this hyper-competitive era.

The big data is controlled by Mappers and Reducers (MR) and to be represented by a processing model where the mapping is processed first followed by reduction as shown in Figure 4. The analytical tasks in MR are written as two functions according to [86] and recently to [87]. It can also be noted that there is an intermediate stage sandwiched between MR's steps. In principle, in the mapper stage, data read, processed, and then used to generate intermediate results. The output of the mapper staged is treated by reducers to finalize results that are stored back to the file system using a platform called Hadoop. The typical Hadoop cluster contains several MRs working simultaneously within a powerful model for batch-processing tasks. The challenge to this model is that the applications require real-time, graph, or iterative processing. This challenge has been encountered by a recent version of Hadoop (Hadoop 2.6.0). In addition to Hado's models, 
there is another model called the Yet Another Resource Negotiator (YARN) which is used to utilize Hadoop towards a new approach for developing a Big Data platform. Under this approach, the service is run by MR over YARN, while YARN handles scheduling and resource management to produce Hadoop that is suitable for implementing innovative applications [19]. YARN is the technology that is designed for cluster management and is one of the key features in the second generation of Hadoop, the Apache Software Foundation's open-source distributed processing framework.

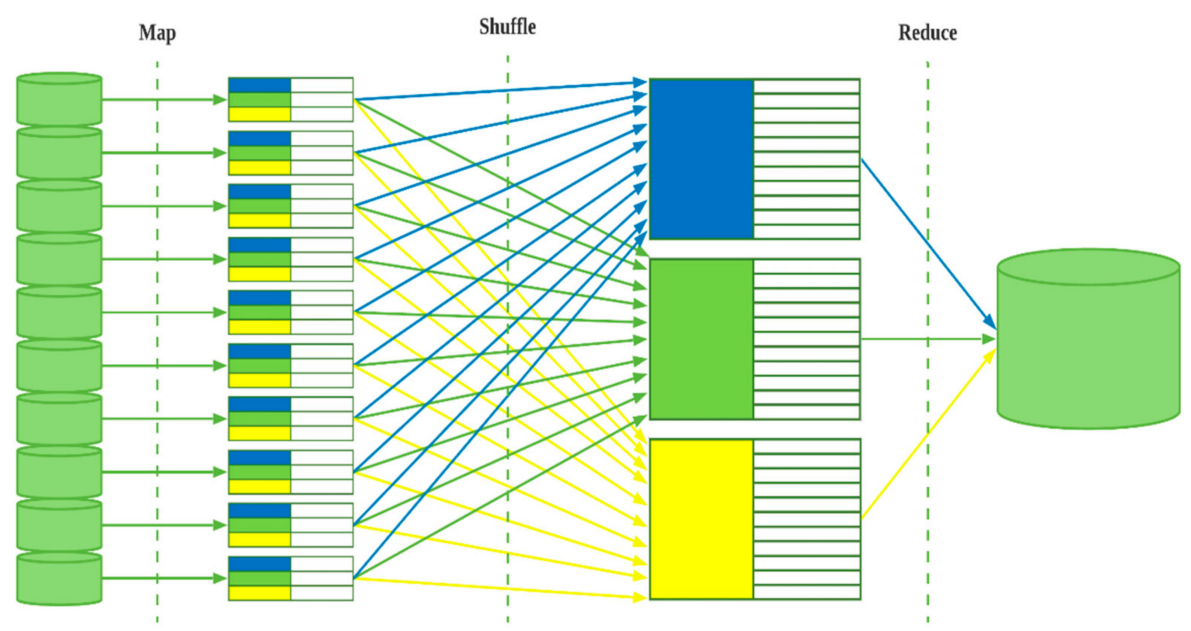

Figure 4. MapReduce processing-an overview [88].

In another development, a new technology called Directed Acrylic Graphs (DAG) has emerged to better handling big data by modifying the model shown in Figure 5 into a map-then-reduce style. The most functioning element in the DAG model is called the Spark, which was originally proposed by [89] and then elaborated by [90]. Spark is characterized by its in-memory computation and high expressiveness [91]. Based on these capabilities, Spark has become a natural choice to support two components of Big Data in iterative and reactive applications [92]. Regarding the speed, Spark has been reported having ten times faster than MR on disk-resident tasks and a hundred times faster for the memory-resident task [93].

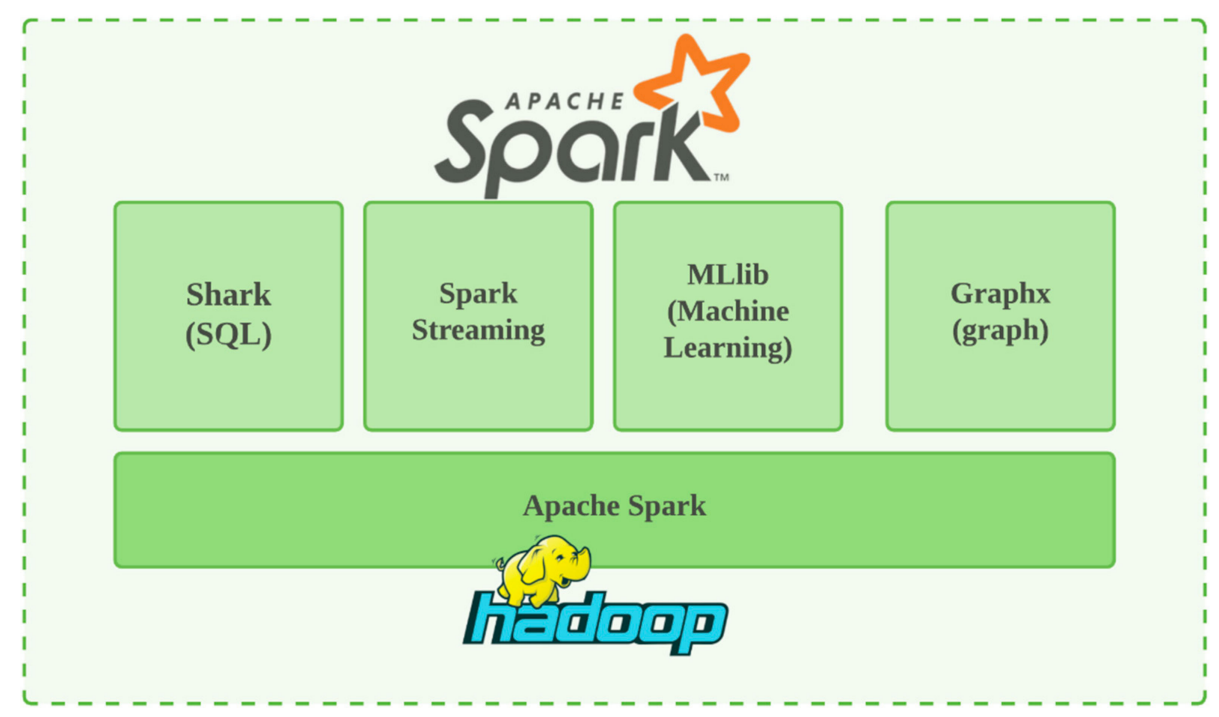

Figure 5. Spark and related technology stack [94]. 
A schematic representation of the architecture and the steps involved in the analytics process of Hadoop and Spark frameworks is shown in Figure 6. The two frameworks involve a new form of MR called elastic MapReduce (EMR), which transfers MR to a system comparable to the cloud [95]. EMR can also run processing frameworks such as Apache Spark and HBase on Hadoop clusters for batch processing, querying, streaming, and machine learning.

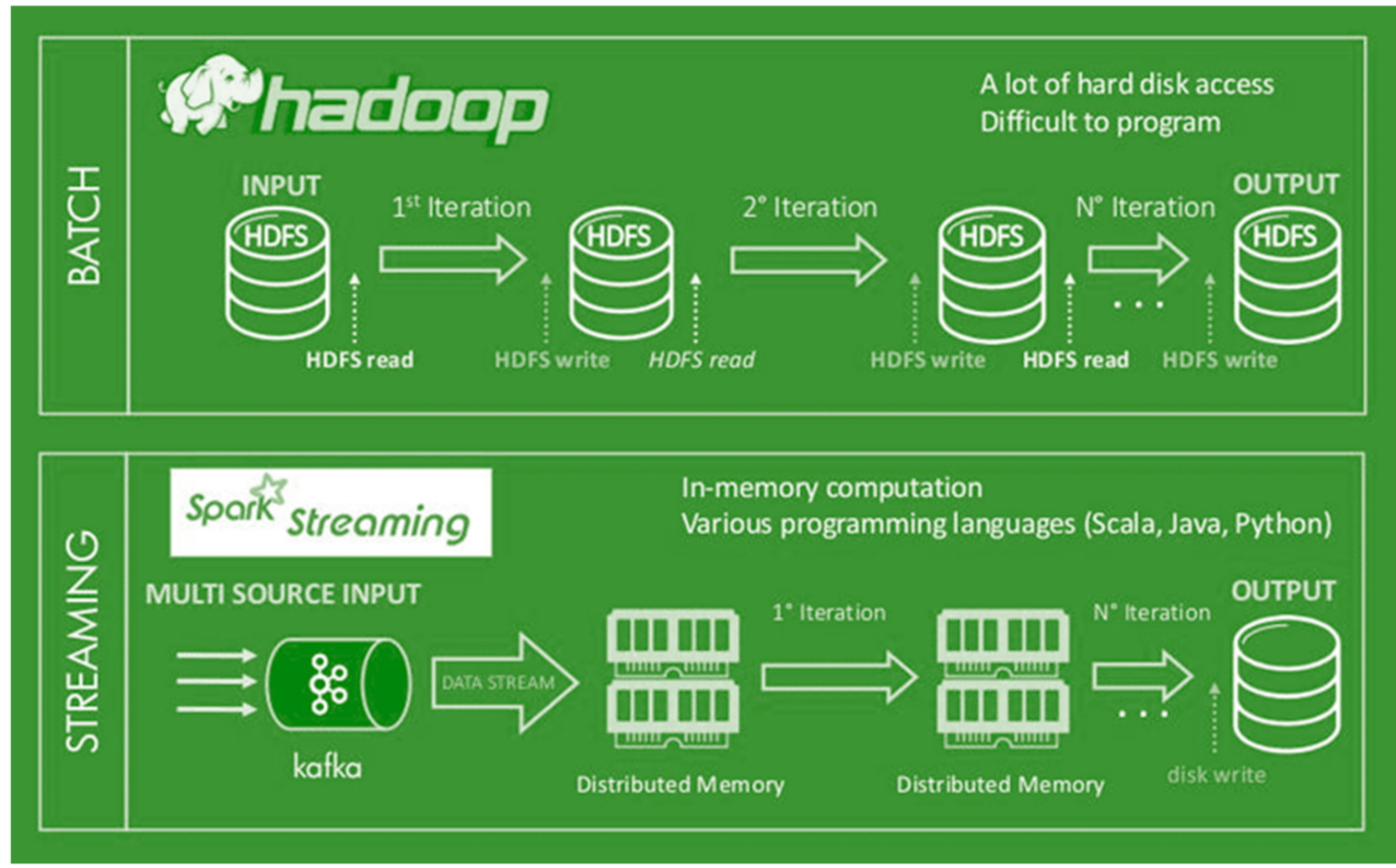

Figure 6. Comparison between Hadoop and Spark [95].

\section{BIM and IoT Devices Integration Approach}

Integrating two or more systems is a very common practice in technology. In this paper, integrating two very advanced technologies, BIM and IoT, requires attention to the following components:

- $\quad$ BIM acts as a data repository for contextual information including building geometry while IoT acts as static and soft information that is gathered from occupancy patterns. In addition, IoT is responsible for scheduling data like social media, feedback originated from FM and occupant interactions, and external sources of information such as weather forecast and financial pricing [96].

- The continuous sensor readings and traditional time-series data (known as time-series data) are stored in a well-structured relational database queried effectively under Structured Query Language (SQL) $[97,98]$. The time-series data is provided by sensors while API is responsible to move data belongs to BMI models constructing tools. The database is to clarify the connection of a two-way connection between virtual objects and physical sensors where data is passing between the database and BIM using APIs [99].

- The third component is about integration between contextual information and timeseries data.

- Integrating BIM and IoT requires an interface technically known as Application Program Interface (API) to correlate data from the sensor and BIM model with evolving database and the two-way importing/exporting data, and queries processing [100]. 


\subsection{BIM-IoT Architecture}

Figure 7 shows a proposed architecture where the data is collected from various heterogeneous IoT sources. The data then undergoes anonymization followed by processing and analysis using the artificial intelligence (AI) technique. The outcome of this data analysis is mainly towards optimization of some parameters of interest aiming at achieving a desired security and performance objectives. The process is carried out in terms of available resources throughout six phases: phase 0 through phase 5 . Phase 0 is to perform security parameters configuration by employing cryptographic algorithms to cater to the confidentiality, integrity, and authentication requirements of the applications and systems using this specific device. Phase 1 is about data sensing and reporting where main IoT classes are distinguished while they will be utilized wither by being wearable devices or IoT appliances. Phase 2 deals with data aggregation and relaying where both need a decision which is target-dependence known as IoT gateway. The third phase (III) involves cloud-based data analysis for the data sent by IoT-gateway. Data analysis is carried out with preserving privacy since this information is made for the general population through Google.

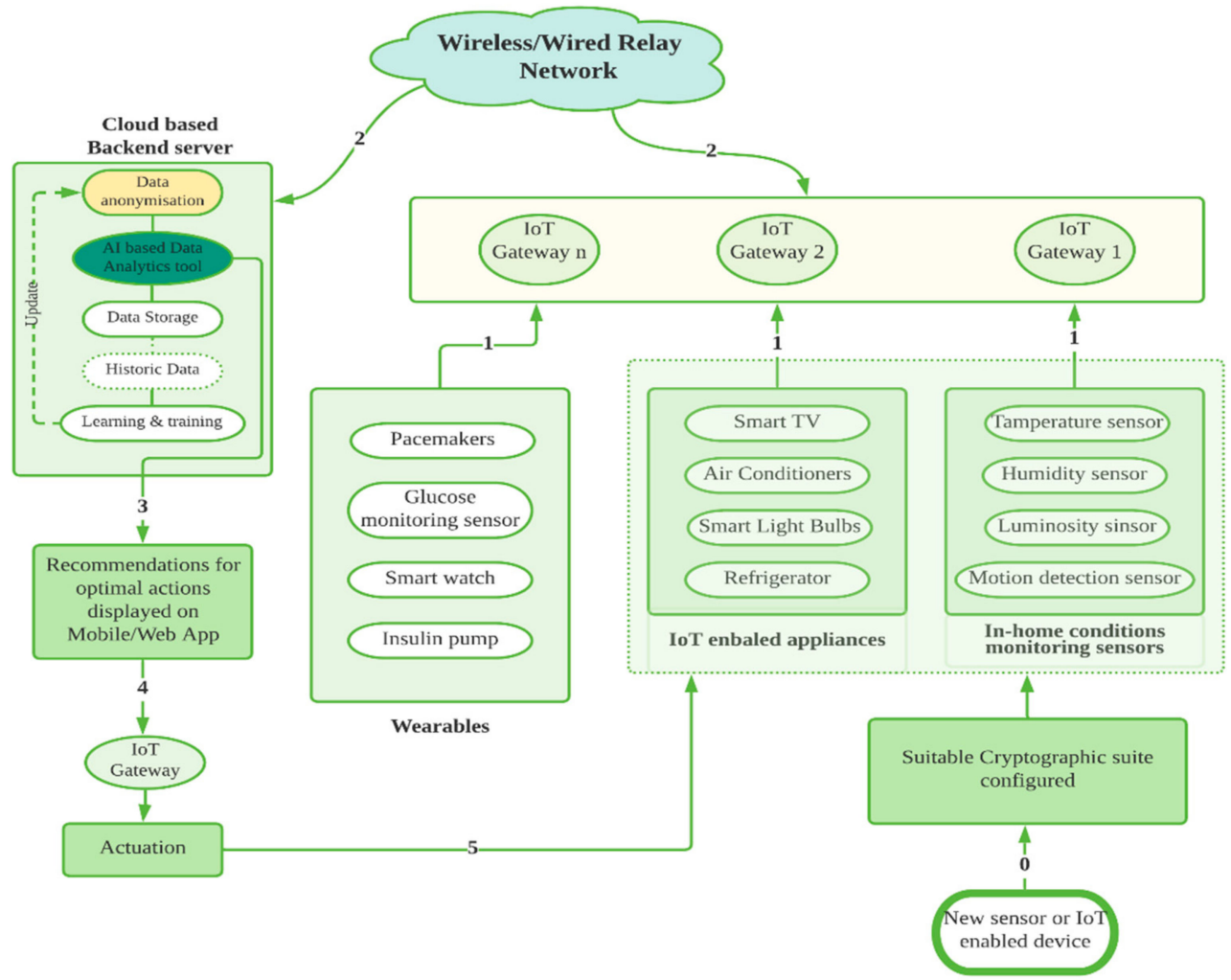

Figure 7. Architecture of a secure and privacy-preserving IoT-based sensing and actuation system [101].

At this level, phase IV is implemented to optimize decision delivery which represents the measure for actuation the system via IoT gateway in terms of mobile or web applications. The last phase is called the actuation phase where instructions should be made to update the configuration file. The degree of actuation could range from changing the upper and lower limits of a given parameter so that reading beyond these limits to trigger an alert and setting conditions under which certain tasks are performed [101]. The phases mentioned above facilitate transferring data into a query-able database. Moreover, the stored data of the traditional building management system can be moved to a well-structured and effective SQL query. This is a fundamental step for binding time-series data with BIM. The linking of 
BIM data can be performed using SQL query-able where connecting virtual sensor objects with physical sensors can be done via a Globally Unique Identifier (GUID) [102].

\subsection{Query Language Approach}

There are several query languages approaches to execute a natural language query (NLQ) and to form a query that is understood by the machines and saved in a database that can be displayed using the graphical user interface (GUI) as shown in Figure 8 [103]. This approach is meant to create a new query language based on processing time-series data query sensor data instead of using SQL as reported by [104]. The authors proposed a domain-specific query language called BIMQL used to modify selected queries from industry foundation classes (IFC)-based BIM models. BIMQL allows object selection and attributes based on arbitrary properties as in IfcSensor despite the limitation in query real-time sensor data [10].

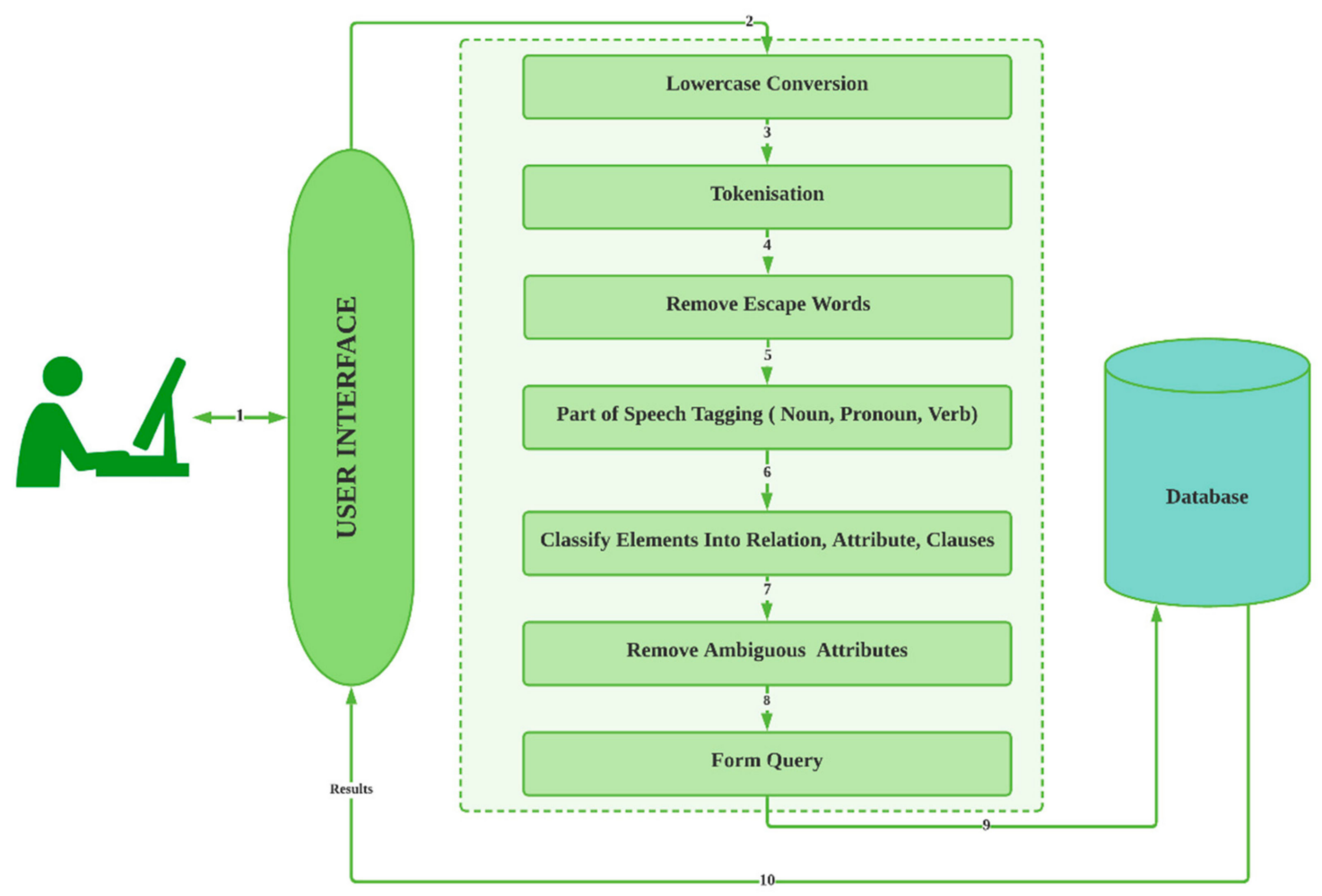

Figure 8. Process control flow diagram [103].

\section{Query Languages}

\subsection{Semantic Web Approach}

In 2000, [105] proposed the CommonKADS methodology which was then introduced to web-oriented knowledge engineering and management. CommonKADS helps in constructing, representing, and accessing appropriately the Web/Grid which becomes recognizable, sharable, and reusable by humans and machines. The methodology of several activities for managing Grid knowledge is shown in Figure 9.

The system is organized in seven phases, i.e., Application Analysis, KM Analysis, Ontology Development, Semantic Annotation, Service Development, Testing and Evaluation, and System Integration. For each of these seven phases, there is a list of tasks called activities which, then, were described by outcomes [106]. The outcome includes a wide variety of activities that range from being attributed to the documents, users, services, testing, and ontologies. In BIM, the task of the sematic web approach is confined to gathering data throughout across building's lifecycle in modern AEC processes is obtained from different sources of data such as building geometry, topology, IoT sensor, and BIM 
geospatial information. Gathering and stores data does not help in offering a full picture. Hence, integrating BIM and semantic web technologies results in acquiring heterogeneous data sets which should be presented in Resource Description Format (RDF) for using and sharing. Moreover, BIM ontologies (IfcOWL) and Smart Appliances Reference ontology (SAREF) can be performed using Semantic Sensor Network (SSN) to successfully approach BIM and IoT device integration [10].

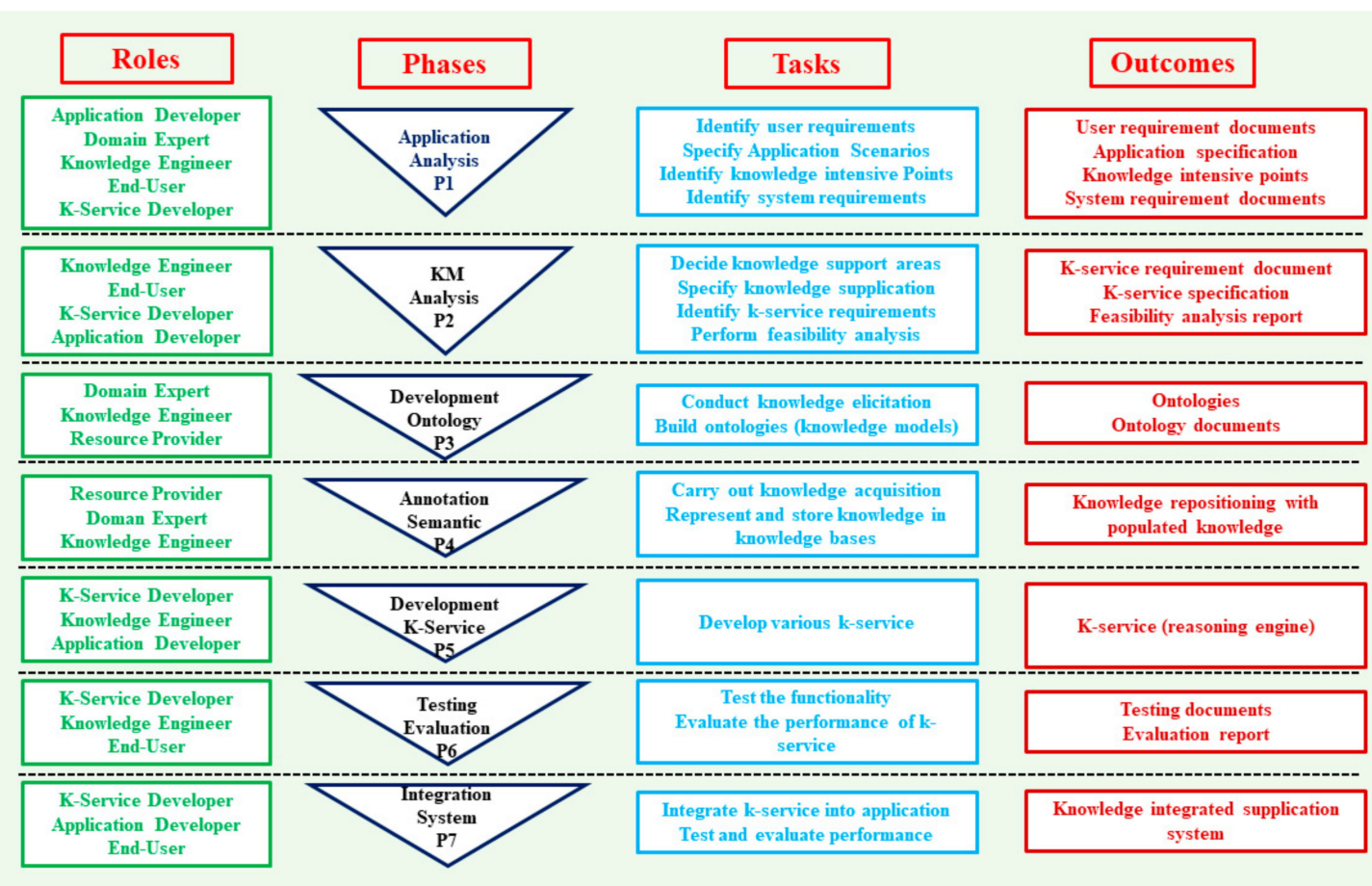

Figure 9. The methodology for the Semantic Web based approach [106].

Based on the discussion of semantic Web-based, an ontology framework named as Onto FM has been proposed to show how monitoring intelligent sensor-based building could fit in this approach [107]. As a complementary process, IFC was introduced to show converting the building geometry into Web Ontology Language (OWL) while using SPARQL to conduct ontology queries. Another study showing a more explicit example of using RDF-Cloud-Linked Data to integrate cross-domain building data from [108]. In addition, other query languages of SQL and XQuery could help in translating SPARQL queries as proposed by [109]. The importance of the monitoring system for real-time data can be seen in other applications fields such as healthcare system [110] and, more broadly in Big Data studies that involve machine learning models, data preprocessing, missing data imputation, and site reliability engineering (SRE) [111].

The advantage of this approach could be seen in linking a homogeneous data format with the cross-domain data. This approach faces some challenges such as storing most of the time-series sensor data in a well-structured and relatively mature relational database, possible data duplication. As a result, converting sensor data in the RDF format leads to RDF inefficiency [109]. The benefit of this approach is to widen the transformation of the knowledge of the semantic web. This benefit represents the possibility of achieving the real concept of interlinking IoT with the Internet via a unified and concise framework provided avoiding complex and heavy data transformation.

\subsection{Hybrid (Semantic Web and Relational Database) Approach}

Hybrid and integration are two different approaches. As hybridization is "working, organizing, or doing something that is composed of elements of two separate systems", the 
integration is "the act of bringing together smaller components into a single system that functions as one" [112]. In the hybrid approach shown in Figure 10, the Semantic Web and relational databases are used to store cross-domain data. Hybridization can be performed through feeding contextual information (building context data, sensor information, and other soft building information) into RDF format using a semantic web approach. Then, retaining sensor (time-series data) in a relational database. The mapping contextual information with time-series data is the last step which can be referenced in terms of sensor ID described in RDF [109].

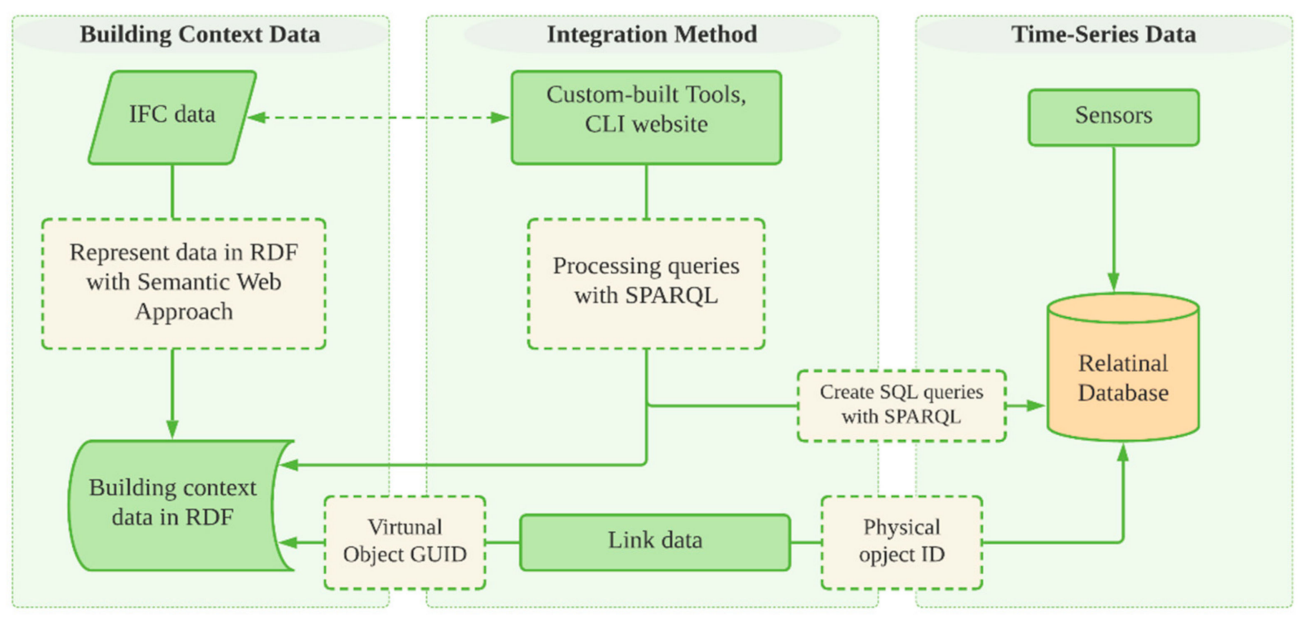

Figure 10. Hybrid approach combining semantic web and relational database [10].

The hybridization method can be performed by converting static sensor information into RDF format to be stored in a relational database and maintained its original form and cross-referenced with SSN ontology to maintain an appropriate platform and format. However, integrating web-hybrid data with BIM still requires modifying sensor data by developing an actuator infrastructure [113]. Hence, any solution is associated with considering integration of the heterogeneous data sources that require building semantic model in RDF format that can be uploaded to a SPARQL server.

The hybrid approach is characterized by involving various data sources retained in the original platforms without influencing the interlinking process. For this reason, hybridization is much effective in storing time-series data while keeping them flexible during building contextual semantic web approach and query. Meanwhile, hybridization has some advantages such as timesaving during storing and duplication, the available size for storing RDF data, better performance, and effective usage of the query language [109]. This approach suggests that it is a very promising method in facilitating IoT integration and it might be suitable for other types of projects that do not require data conversion.

\subsection{Limitation and Challenging of BIM-IoT Integration \\ 6.3.1. Limitations}

$\mathrm{BIM}$ and IoT are new technologies; however, integrating IoT and BIM in construction engineering is another, yet, much-advanced technology. This integration offers the setting of data originated from BIM and IoT as complementary for creating a project. As explained in the preceding sections that BIM and IoT can be integrated; however, this integration has some limitations or restrictions [114].

Individually, the BIM model limitation is related to approaching the component level with high-reliability representations. Generally, BIM models are a very good source for incorporating geometry, spatial location, and a scalable set of metadata properties which, collectively, provide a high-reliability operable dataset. The operable dataset offers suitable conditions for building design by incorporating the spatial organization as a set of virtual 
assets [115]. IoT data, on the other side, enhances the information set due to employing real-time and recordable status taken physically from real construction operations.

The sensors, sensitive parts of high-tech devices, are a reliable source of sampling potential information from sensors. The data sampling includes three sectors: measurements of the physical building, weather information from official records, and the information from high-tech devices [116]. The characteristics of the data obtained by sensors are series streams distributed over time and frequently at a high-level. The stored IoT and BIM data is accessible through manual interfaces of proprietary systems or programming APIs associated with these applications.

The database provides accessible data export to the systems via open standards that regulate both BIM and IoT fields [10]. The other application of the adoption of BIM and IoT devices was in aspects such as energy management, construction monitoring, health, and safety management, and building management. It is important to note that implementing BIM-IoT is still in the early stages and most studies are in the conceptual and theoretical domain [117]. IoT integration in BIM cannot be considered as merely involving IoT devices (sensors or actuators), but the goal is to interconnect IoT devices to gather the information that can be shared on the Internet. To challenge the system design, a novel robust framework for the energy scheduling of a residential microgrid is connected via smart users [118]. The main current problem of BIM-IoT integration is the difficulty of sharing this information across the Internet under a unified framework [10]. The situation now is that the integration of BIM and IoT device is scattered and need more research to be sufficiently matured in terms of patterns, issues, and opportunities [119]. The smart energy management system has been applied in construction in terms of controlling both heat and electricity using the principle of integrating various types of flexible appliances as well as hybrid energy appliances [120].

The integration of BIM and IoT may provide a source of information that can impact facilitating BIM as a result of installing the smart-nature IoT in the building's spaces. The results could provide very important information concerning the status of both the spaces and devices. The facility management (FM) organizations may benefit from this live data to deliver more added value services to BIM-IoT integration [121]. The possible success of BIM-IoT integration, however, still face barriers to benefit from the live data concept. In this case, two barriers may arise; a major barrier is originated from the fact that the live data are still scattered across heterogeneous storage, while the second barrier comes from a situation that appeared as fragmented systems scattered across space planning, the maintenance helpdesk, the building management system, and the facility management. The implication of these two barriers is complicating the efforts and causing inaccessible data due to the non-standardization data input and the lack of standard processes and procedures for capturing and recording the building information [10]. As such, the absence of standard methods or procedures for capturing data results in forcing FM staff to develop methods and procedures that do not necessarily coincide with the nature of BIM and IoT integration [122].

The absence of combining building the space information and the live data may complicate the task available for FM companies. Hence, research equipped with suitable surveys found in literature aiming at exploring the origins and impacts of the barriers mentioned above on the efficiency of the services. Reference [123] underlined that FM activities require both accuracy and accessibility of the created data in the design and construction stages. However, [124] pointed out the importance of preparing management and organizing competencies for the importance of the FM activities to the managerial procedure.

Meanwhile, the explored barriers can be eradicated hoping to make possible improvements to enhance the overall efficiency of the staff activities and minimizing the time spent on individual tasks. Furthermore, eradicating barriers could lead to enhance the performance of the staff by reducing the required time for establishing the accuracy of the available building information. The saved time may be used to improve the task at 
hand such as monitoring the use of energy. Then, the overall improvement of lifecycle management can be achieved with a reduction in the operational costs. The benefits of the proposed solution are described in the form of practical use cases [6].

\subsubsection{Sensors Challenges}

Generating BIM for existing buildings is no easy task; it is very complicated and expensive due to the current and emerging challenges in preparing the required data, modelling, and processing semantic memory [125]. In addition, the BIM's level of detail (LoD) may add more complexities to O\&M and FM functionalities [57,88].

The generation of as-built information for creating BIM requires the acquisition technologies which rely on Digital Photogrammetry (DG), Terrestrial Laser Scanner (TLS), and Ground Penetrating Radar (GPR), which, collectively, provide the geometric information of the object. The role of DG is to capture still images and then expressing them in 3D point clouds. Moreover, TLS is to estimate how far the scanner from the target by using multiple points of amplified light. Lastly, GPR equipped with a high-frequency radio signal can infer the location of embedded objects. According to [126], as-built data acquisition requires involving on-site labs furnished with manual or visual measurement assessment. The main challenge of DG, TLS, or GPR shows high-error and requires a long time. Hence, with the poor reliability of these techniques, significant uncertainty is created for decision-makers [127].

To minimize the error created by DG, TLS, and GPR, a series of precautionary steps should be considered. For DG, it is preferable to use simultaneous two 3D cameras to detect the coordinates of the object. The data available creates at least two converging lines to identify a point in space by using several inputs representing coordinates $(X, Y$, and $Z)$ and the angle of rotation of the cameras $(\omega, \psi$, and $k)$. Despite this precautionary step, several problems and challenges still exist such as the sensitivity of DG to the changing light conditions during the daytime by introducing shadow which affects the alignment of photos. The other problem is occlusion and the noise in image sensors [128]. The third challenge is the inability of the cameras to provide an absolute scale for distances [129].

Secondly, regarding TLS, the emission of pulses of light to the surface of the object of interest suffers from reflection captured by the sensors causing an error in the derived distance [130]. Hence, replacing old TLS with a more sophisticated TLS can capture more features to better estimate the distances [131]. However, this technique is not suitable for long ranges because of expanding the spot which creates multiple returns causing problems with partial occlusions. Lastly, GPR has been used to identify the location of buried utilities [132] and inspect concrete structures [133].

However, during emitting light to penetrate objects, there will multiple reflections that affect the quality of the images and the measured distance. GPR is limited to detect objects up to $30 \mathrm{~m}$ depending on the frequency of the radio signal used. A solution has been proposed to eliminate the multiple reflections was proposed earlier using coupled antennas [132]. Figure 11 shows the employed methodology which includes different non-destructive testing (NDT) techniques for characterization of the outdoors, indoors, and internal structure besides the elements involved.

The process combines all the 3D as-is structure matters such as geometry and materials and the irregularities that affect the structure or the used materials. The external surface geometry and its spectral properties were determined using a camera mounted on a unmanned aerial systems (UAS). The visible pathologies of the façade were also identified from RGB (red, green, and blue) imaging. To complement this information, a GPR system was employed to examine the façade interior (through-the-thickness) while infrared thermography images (IRT) was applied to the nearest sub-surface. All the gathered information, properly georeferenced, was fed to a 3D model obtained by a TLS technique and supported by a BIM model elaborated in Autodesk Revit. Information obtained with other techniques (either NDT or more intrusive) can obviously also be integrated into this BIM model [134]. 


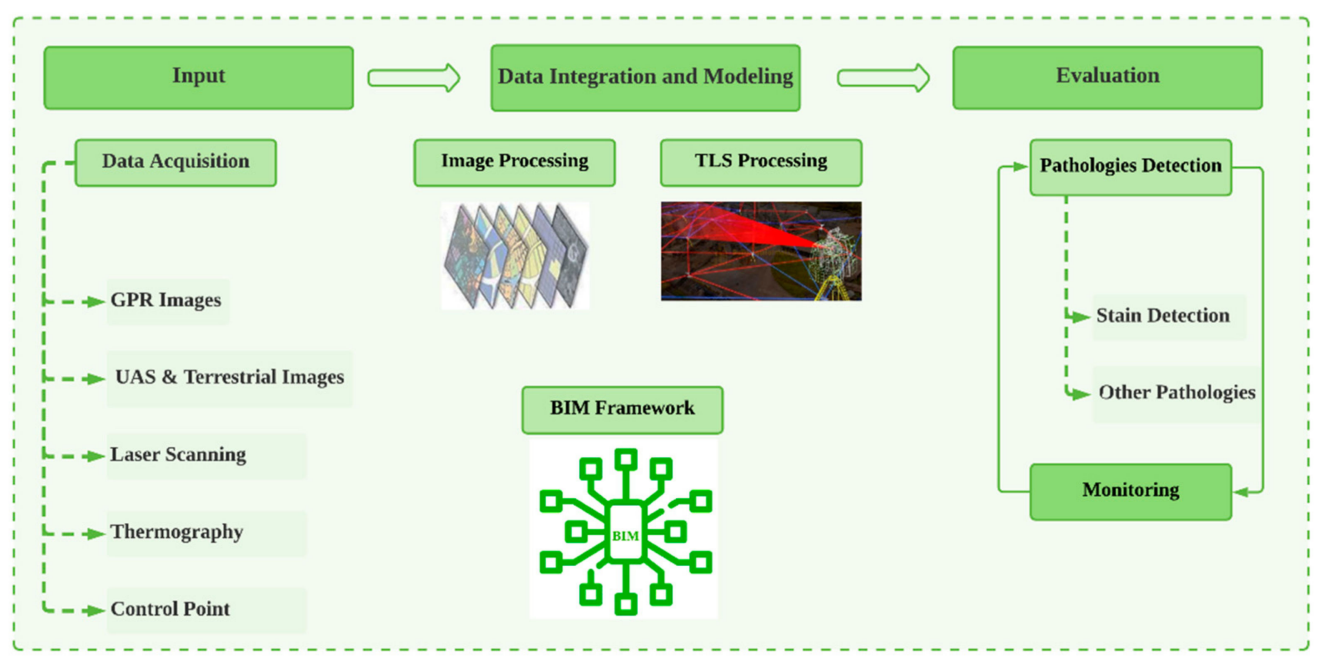

Figure 11. As-built information for creating BIM using Digital Photogrammetry (DG), Terrestrial Laser Scanner (TLS), and Ground Penetrating Radar (GPR) [134].

\subsection{Devising a New Approach for IoT-BIM Integration}

\subsubsection{Framework of BIM and Sensor Integration}

An attempt was made to formalize a theoretical framework to integrate information theories with knowledge management. The first item in this formalization is establishing an end-user conceptual framework of BIM and sensors in which the knowledge layer is located from data provided by occupants [135]. The more visionary descriptions from the end-users could identify the best connection of IoT or enhance the ability to collect and analyze data towards sharing information across platforms [7].

In a previously conceptualized framework, analytical activity is not thoroughly explicated [136]. In addition, integrating data from the warehouse, for example, was the only part mentioned without illustrating and emphasizing the analytic functionality of this layer. This could be resulted in by the complication of this new integration. The systematic approach for the conceptual framework is shown in Figure 12. There are four layers that satisfy the pyramid hierarchy of [137].

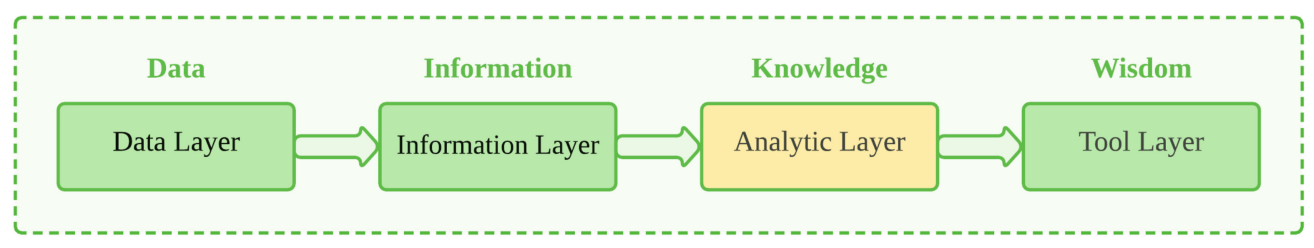

Figure 12. Framework of integration follows the knowledge management model [136].

The four layers mentioned in Figure 11 were connected to a set of data information that belongs to the indoor environmental factors such as noise, temperature, air quality, light, etc. The environment data can be used before merging to other information from different sources in analytic activities. This set-point has been used to analyze the data from the sensors that belong to several facility management. The whole set of data information is explained in Figure 13.

\subsubsection{Implementing Service-Oriented Architecture}

The future approach relies on implementing the Service-Oriented-Architecture (SOA) whose features include service composition, service discovery, asset wrapping, modeldriven implementation, loosely coupled, and platform-independent. SOA combines designing software and other services are combined aiming at providing large application functionalities through a communication protocol. SOA's features are very helpful in 
reducing the complexities of integrating IoT smart devices in BIM. The current proposals of IoT-BIM integration are not satisfactory in generating a unified architecture system for integrating IoT devices in BIM [138-140]. The goal of any new proposal of IoT-BIM integration should consider a new design where data exchange between SOA, web sites services, and integration methods. The new design should be highlighted by a new representation called representational state transfer (REST) in which only IoT nodes are utilized in the process [135].

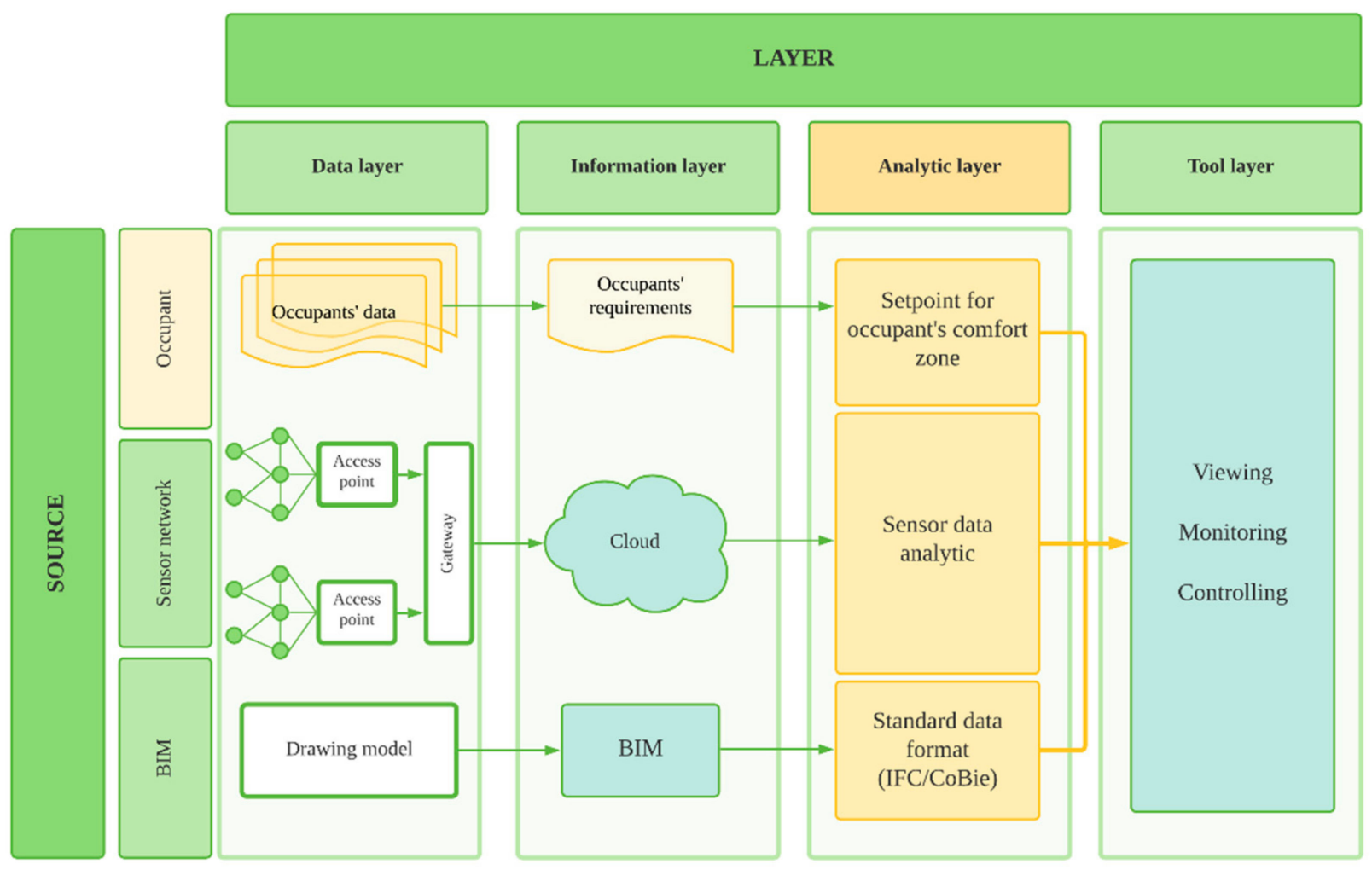

Figure 13. Framework of BIM and sensor integration to improve building performance for occupants' perspective [136].

The first item in developing a new IoT-BIM integration is to reconsider the sematic information of BIM that failed to display elements of indoor conditions. The link of updating static models towards real-time models is necessary to be taken into account. This step results in developing new SOA patterns through which BIM can update the reading of IoT devices. This step requires a system that can do four operations of creating, reading, updating, and deleting (CRUD). The CRUD operations still need heavy investigation. Another point to achieve better IoT-BIM integration is enabling IoT devices to read from models using fusing multi-source information in SOA patterns. Currently, this fusion is carried out by one-way interaction, which develops mimic the human-two-way approach by offering algorithms characterized by human cognitive buildings [141].

Recently, researchers have been focusing on confining the heterogeneous data sources and apply them into different domains to serve intended purposes [77]. Meanwhile, certain issues should be considered such as information consistency, traceability, and archiving [142]. Solving these issues has been proposed by the National Institute of Standards and Technology (NIST) by issuing a framework for Cyber-Physical System (CPS). CPS is a huge system where dimensions such as common language, architecture foundations, and taxonomy are fused to better exchanging ideas and, meanwhile, developing new IoT applications that can be integrated easily with BIM. This approach requires providing comprehended data to handle by the AEC industry. It includes evaluating the query 
representations within cross-domain data sets, managing collected data for the highest utilization, and assuring a unified information flow during the building lifecycle [143].

In the above approaches of IoT integration, IoT was purely considered as highly related to sensors and actuators. The concept of IoT could be far from these specific issues as new information tools are needed to interconnecting sensors and actuators. This is a high-tech approach that requires highly involving Cloud computations to better connect IoT devices throughout Internet infrastructure [140]. For this reason, Cloud can be adopted in the AEC industry. Currently, most sensors are not connected using Cloud and in this new framework, sensors should be identified and connected in terms of Cloud computing.

The above discussion opens the way to achieve building a system that involves IoT, BIM, and Cloud. Hence, developing generic architecture could be very valuable in building applications that share common requirements and characteristics for the future of BIM.

\section{Summary of Previous Empirical Research}

Table 2 shows the most recent journal papers that aligned with the contents and the purposes of this current review paper. The first purpose is to integrate data into BIM. It has been proposed integrating cloud data and hyperspectral imaging using high-tech instrumentations equipped with laser and 3D-technique [12]. The study showed that such integration was successfully performed for management facilities. In previous moves, [19] integrated big data in the construction industry to provide new opportunities and future trends. In their attempt, they used a huge number of publications that were collected during the years around 2016. The review concludes that Big Data could have a potential approach to treat the potential pitfalls associated with Big Data adoption in the industry.

Table 2. Summary of previous empirical research.

\begin{tabular}{|c|c|c|c|c|}
\hline Specifications & Purpose & Methodology & Main Points & Conclusions \\
\hline $\begin{array}{l}\text { [12] Integration of point } \\
\text { cloud data and } \\
\text { hyperspectral imaging } \\
\text { as a data gathering } \\
\text { methodology for } \\
\text { refurbishment projects } \\
\text { using Building } \\
\text { Information Modelling } \\
\text { (BIM). Journal of } \\
\text { Facilities Management, } \\
\text { 17(1), 57-75 }\end{array}$ & $\begin{array}{l}\text { Integration of point } \\
\text { cloud data and } \\
\text { hyperspectral imaging } \\
\text { as a data gathering } \\
\text { methodology for } \\
\text { refurbishment projects } \\
\text { using building } \\
\text { information modelling } \\
\text { (BIM). Journal of } \\
\text { Facilities Management. }\end{array}$ & $\begin{array}{l}\text { Laser scanning can be used to } \\
\text { collect geometrical and spatial } \\
\text { information in the form of a 3D } \\
\text { point cloud, and this technique is } \\
\text { already used. However, as a point } \\
\text { cloud representation does not } \\
\text { contain any semantic information } \\
\text { or geometrical context, such point } \\
\text { cloud data must refer to external } \\
\text { sources of data, such as building } \\
\text { specification and construction } \\
\text { materials, to be in used in BIM. }\end{array}$ & $\begin{array}{c}\text { Hyperspectral imaging } \\
\text { techniques can be applied to } \\
\text { provide both spectral and } \\
\text { spatial information of scenes as } \\
\text { a set of high-resolution images. } \\
\text { Integrating of a 3D point cloud } \\
\text { into hyperspectral images } \\
\text { would enable accurate } \\
\text { identification and classification } \\
\text { of surface materials and would } \\
\text { also convert the 3D } \\
\text { representation to BIM }\end{array}$ & $\begin{array}{l}\text { This integrated approach was } \\
\text { applied in facilities management } \\
\text { and construction to improve the } \\
\text { efficiency and automation of the } \\
\text { data transition from building } \\
\text { pathology to BIM. This study } \\
\text { integrates laser scanning and } \\
\text { hyperspectral imaging. In } \\
\text { addition, the study uses a new } \\
\text { integration technique which is } \\
\text { applied for the first time in the } \\
\text { context of buildings. }\end{array}$ \\
\hline $\begin{array}{l}\text { [19] Big Data in the } \\
\text { construction industry: } \\
\text { A review of present } \\
\text { status, opportunities, } \\
\text { and future trends. } \\
\text { Advanced engineering } \\
\text { informatics, } 30(3), \\
500-521 .\end{array}$ & $\begin{array}{l}\text { Integrate big data in the } \\
\text { construction industry to } \\
\text { provide new } \\
\text { opportunities and } \\
\text { future trends. }\end{array}$ & $\begin{array}{l}\text { Related works were reviewed based } \\
\text { on publications of the databases of } \\
\text { American Association of Civil } \\
\text { Engineers (ASCE), Institute of } \\
\text { Electrical and Electronics Engineers } \\
\text { (IEEE), Association of Computing } \\
\text { Machinery (ACM), and Elsevier } \\
\text { Science Direct Digital Library. }\end{array}$ & $\begin{array}{l}\text { This paper fills the void and } \\
\text { presents a wide-ranging } \\
\text { interdisciplinary review of } \\
\text { literature of fields such as } \\
\text { statistics, data mining and } \\
\text { warehousing, machine } \\
\text { learning, and Big Data } \\
\text { Analytics in the context of the } \\
\text { construction industry. }\end{array}$ & $\begin{array}{l}\text { The current state of adoption of } \\
\text { Big Data in the construction } \\
\text { industry was reviewed. Future } \\
\text { potential of Big Data across the } \\
\text { multiple domain-specific } \\
\text { sub-areas of the construction } \\
\text { industry. The review concludes } \\
\text { that Big Data could have } \\
\text { potential approach to treat the } \\
\text { potential pitfalls associated with } \\
\text { Big Data adoption in the industry. }\end{array}$ \\
\hline $\begin{array}{l}\text { [122] Towards a } \\
\text { semantic Construction } \\
\text { Digital Twin: Directions } \\
\text { for future research. } \\
\text { Automation in } \\
\text { Construction, } \\
\text { 114, 103179. }\end{array}$ & $\begin{array}{l}\text { Implementing a } \\
\text { semantic Construction } \\
\text { Digital Twin: Directions } \\
\text { for future research. }\end{array}$ & $\begin{array}{l}\text { Introducing a standardized } \\
\text { semantic representation of building } \\
\text { components and systems using the } \\
\text { Digital Twin conveys. Digital Twin } \\
\text { is characterized by socio-technical } \\
\text { and process-oriented } \\
\text { characterization of the } \\
\text { complex artefacts. }\end{array}$ & $\begin{array}{l}\text { The review discusses the } \\
\text { multi-faceted applications of } \\
\text { BIM during the construction } \\
\text { stage and highlights limits and } \\
\text { requirements, paving the way } \\
\text { to the concept of a } \\
\text { Construction Digital Twin. }\end{array}$ & $\begin{array}{l}\text { The study adopted the Digital } \\
\text { Twin paradigm in the } \\
\text { construction industry sector. Due } \\
\text { to this technology, the concept of } \\
\text { BIM gained sufficient recognition } \\
\text { and momentum to enable a shift } \\
\text { from a static, closed information } \\
\text { environment to a dynamic. }\end{array}$ \\
\hline $\begin{array}{l}\text { [30] BIM integrated } \\
\text { smart monitoring } \\
\text { technique for building } \\
\text { fire prevention and } \\
\text { disaster relief. } \\
\text { Automation in } \\
\text { Construction, 84, 14-30. }\end{array}$ & $\begin{array}{l}\text { To integrate smart } \\
\text { monitoring technique } \\
\text { for building fire } \\
\text { prevention and disaster } \\
\text { relief BIM. }\end{array}$ & $\begin{array}{l}\text { BIM was used to construct a } \\
\text { BIM-based Intelligent Fire } \\
\text { Prevention and Disaster Relief } \\
\text { System. The methodology uses } \\
\text { personal localization, on } \\
\text { evacuation/rescue route } \\
\text { optimization with Bluetooth-based } \\
\text { technology, and on a mobile } \\
\text { guidance device to create an } \\
\text { intelligent and two-way fire } \\
\text { disaster prevention system. }\end{array}$ & $\begin{array}{l}\text { The results of applying the } \\
\text { BIM-based system } \\
\text { demonstrate that it may } \\
\text { effectively provide 3D } \\
\text { visualization to support the } \\
\text { assessment and planning of } \\
\text { fire safety. }\end{array}$ & $\begin{array}{l}\text { The study contributes with } \\
\text { providing early detection and } \\
\text { alarm responses that is used for } \\
\text { efficient evacuation and to } \\
\text { facilitate fire rescue and control } \\
\text { efforts in order to increase overall } \\
\text { building safety and } \\
\text { disaster-response capabilities. }\end{array}$ \\
\hline
\end{tabular}


Table 2. Cont.

\begin{tabular}{|c|c|c|c|c|}
\hline Specifications & Purpose & Methodology & Main Points & Conclusions \\
\hline $\begin{array}{l}\text { [50] Building Information } \\
\text { Modeling (BIM) for } \\
\text { transportation } \\
\text { infrastructure-Literature } \\
\text { review, applications, } \\
\text { challenges, and } \\
\text { recommendations. } \\
\text { Automation in } \\
\text { Construction, 94, 257-281. }\end{array}$ & $\begin{array}{l}\text { Using BIM for } \\
\text { improving the } \\
\text { transportation } \\
\text { infrastructure. }\end{array}$ & $\begin{array}{c}\text { Develop more efficient and } \\
\text { cost-effective techniques } \\
\text { necessary to repair, advance, and } \\
\text { expand the } \\
\text { transportation infrastructure. }\end{array}$ & $\begin{array}{l}\text { The results show that the use } \\
\text { of BIM for transportation } \\
\text { infrastructure has been } \\
\text { increasing. More specifically, } \\
\text { the research has mainly been } \\
\text { focusing on roads, highways, } \\
\text { and bridges. }\end{array}$ & $\begin{array}{l}\text { There is a major need for a } \\
\text { standard neutral exchange format } \\
\text { and schema to promote } \\
\text { interoperability. In addition, the } \\
\text { continuing collaboration between } \\
\text { academia and industry is } \\
\text { required to mitigate most } \\
\text { challenges and to realize the full } \\
\text { potential of BIM for } \\
\text { transportation infrastructure. }\end{array}$ \\
\hline $\begin{array}{l}\text { [117] A framework for } \\
\text { integrating BIM and IoT } \\
\text { through open standards. } \\
\text { Automation in } \\
\text { Construction, 95, 35-45. }\end{array}$ & $\begin{array}{l}\text { To create diverse fields } \\
\text { including BIM, } \\
\text { information system, } \\
\text { Automation Systems, } \\
\text { and IoT devices for the } \\
\text { end users. }\end{array}$ & $\begin{array}{l}\text { The methodology is to integrate } \\
\text { the data with IoT sensors and } \\
\text { web-based system called } \\
\text { Otaniemi3D to integrate BIM and } \\
\text { IoT devices through open } \\
\text { messaging standards open } \\
\text { message interface (O-MI) ad open } \\
\text { data format (O-DF) and } \\
\text { IFC models. }\end{array}$ & $\begin{array}{l}\text { The paper describes the design } \\
\text { criteria, the system } \\
\text { architecture, the workflow, and } \\
\text { a proof of concept with } \\
\text { potential use cases that } \\
\text { integrate IoT with the } \\
\text { built environment. }\end{array}$ & $\begin{array}{l}\text { The end users and other research } \\
\text { groups can benefit from such } \\
\text { platforms by either consuming } \\
\text { the data in their daily life or using } \\
\text { the data for more } \\
\text { advance research. }\end{array}$ \\
\hline $\begin{array}{c}\text { [9] Design and } \\
\text { implementation of a novel } \\
\text { service management } \\
\text { framework for IoT devices } \\
\text { in cloud. Journal of } \\
\text { Systems and Software, } \\
119,149-161 .\end{array}$ & $\begin{array}{l}\text { Adopting smart objects } \\
\text { to transmit data to the } \\
\text { cloud for processing } \\
\text { and storage } \\
\text { through IoT. }\end{array}$ & $\begin{array}{l}\text { Combining the cloud computing } \\
\text { environment with IoT to reduce } \\
\text { the transmission and processing } \\
\text { cost in the cloud and to provide } \\
\text { better services for processing and } \\
\text { storing the real time data } \\
\text { generated from those IoT devices. }\end{array}$ & $\begin{array}{l}\text { The proposed cloud } \\
\text { framework combines IoT and } \\
\text { cloud environment to provide } \\
\text { services to both IoT and } \\
\text { non-IoT users. }\end{array}$ & $\begin{array}{l}\text { A novel framework is designed } \\
\text { for the cloud to manage the real } \\
\text { time IoT data and scientific } \\
\text { non-IoT data. The other part of } \\
\text { the framework is cloud, where } \\
\text { data storage and process are } \\
\text { carried out depending on the } \\
\text { user requirement. }\end{array}$ \\
\hline $\begin{array}{l}\text { [55] Automatic } \\
\text { reconstruction of 3D } \\
\text { building models from } \\
\text { scanned 2D floor plans. } \\
\text { Automation in } \\
\text { Construction, 63, 48-56. }\end{array}$ & $\begin{array}{l}\text { To significantly improve } \\
\text { the systematic use of } \\
\text { Information and } \\
\text { Communication } \\
\text { Technologies (ICT) tools } \\
\text { and BIM. }\end{array}$ & $\begin{array}{l}\text { The present article introduces a } \\
\text { research work aiming at the } \\
\text { development of methods for the } \\
\text { generation of 3D building models } \\
\text { from 2D plans. }\end{array}$ & $\begin{array}{l}\text { A prototype can extract } \\
\text { information from } 2 \mathrm{D} \text { plans and } \\
\text { to generate IFC to include the } \\
\text { main components of the } \\
\text { building: walls, openings, } \\
\text { and spaces. }\end{array}$ & $\begin{array}{l}\text { Results are very promising and } \\
\text { show that such solutions could be } \\
\text { key components of future digital } \\
\text { toolkits for renovation design. }\end{array}$ \\
\hline $\begin{array}{l}\text { [109] Building } \\
\text { performance optimization: } \\
\text { a hybrid architecture for } \\
\text { the integration of } \\
\text { contextual information } \\
\text { and time-series data. } \\
\text { Automation in } \\
\text { Construction, 70, 51-61. }\end{array}$ & $\begin{array}{l}\text { To build sematic data } \\
\text { for better feasibility of } \\
\text { creating adapters } \\
\text { between many different } \\
\text { software tools. }\end{array}$ & $\begin{array}{l}\text { Presenting a new solution to the } \\
\text { semantic data by a hybrid } \\
\text { architecture that links data which } \\
\text { is retained in its original format. } \\
\text { The architecture links existing } \\
\text { and efficient relational databases } \\
\text { storing time-series data and } \\
\text { semantically described building } \\
\text { contextual data. }\end{array}$ & $\begin{array}{l}\text { The main contribution of this } \\
\text { work is an original RDF syntax } \\
\text { structure and ontology to } \\
\text { represent existing database } \\
\text { schema information, and a new } \\
\text { mechanism that automatically } \\
\text { prepares data streams for } \\
\text { processing by rule-based } \\
\text { performance definitions. }\end{array}$ & $\begin{array}{l}\text { The hybrid architecture avoids } \\
\text { the duplication of time-series } \\
\text { data and overcomes some of the } \\
\text { differences found in database } \\
\text { schemas and database platforms. }\end{array}$ \\
\hline $\begin{array}{l}\text { [144] An IoT-based } \\
\text { autonomous system for } \\
\text { workers' safety in } \\
\text { construction sites with } \\
\text { real-time alarming, } \\
\text { monitoring, and } \\
\text { positioning strategies. } \\
\text { Automation in } \\
\text { Construction, 88, 73-86. }\end{array}$ & $\begin{array}{l}\text { To protect construction } \\
\text { workers and prevent } \\
\text { accidents in such sites. }\end{array}$ & $\begin{array}{c}\text { The design of the wearable } \\
\text { device includes a set of } \\
\text { components which are a radio } \\
\text { transceiver } \\
\text { (transmitter/receiver), a wake-up } \\
\text { sensor, an alarm actuator, and a } \\
\text { General Packet Radio Service } \\
\text { (GPRS) module. }\end{array}$ & $\begin{array}{c}\text { The heterogeneous } \\
\text { components of this architecture } \\
\text { are seamlessly integrated into a } \\
\text { middleware backend } \\
\text { online server. } \\
\text { The wearable device has a } \\
\text { power saving scheme with a } \\
\text { current consumption as low as } \\
0.5 \mu \mathrm{A} \text { at } 3 \mathrm{~V} \text {. }\end{array}$ & $\begin{array}{l}\text { Presenting an implementation of } \\
\text { wireless nodes that are powered } \\
\text { by light energy using } \\
\text { photovoltaic cells. These nodes } \\
\text { adopt energy management and } \\
\text { storage schemes for continuous } \\
\text { operation for indoor and } \\
\text { outdoor environments. }\end{array}$ \\
\hline $\begin{array}{l}\text { [119] Top } 10 \text { technologies } \\
\text { for indoor positioning on } \\
\text { construction sites. } \\
\text { Automation in } \\
\text { Construction, 118, } 103309 .\end{array}$ & $\begin{array}{l}\text { Demonstrating indoor } \\
\text { positioning enables five } \\
\text { significant applications } \\
\text { that considerably } \\
\text { enhance work efficiency } \\
\text { and safety on } \\
\text { construction sites }\end{array}$ & $\begin{array}{l}\text { Indoor positioning systems can } \\
\text { be viewed as a combination of (1) } \\
\text { creating corresponding } \\
\text { algorithms, (2) indoor positioning } \\
\text { technologies, and (3) indoor } \\
\text { positioning hardware equipment. }\end{array}$ & $\begin{array}{l}\text { Full analysis for challenges in } \\
\text { applying six indoor } \\
\text { positioning systems on } \\
\text { construction sites. The system } \\
\text { was to include technologies } \\
\text { and principles. }\end{array}$ & $\begin{array}{l}\text { A promising trends of indoor } \\
\text { positioning development for } \\
\text { indoor positioning hybridization } \\
\text { was created using game theory } \\
\text { positioning, and integration with } \\
\text { BIM model. }\end{array}$ \\
\hline $\begin{array}{l}\text { [37] Metadata Models and } \\
\text { Methods for Smart } \\
\text { Buildings (Doctoral } \\
\text { dissertation, } \\
\text { UC San Diego). }\end{array}$ & $\begin{array}{l}\text { To use an effective } \\
\text { sensing data and } \\
\text { Heating, ventilation, } \\
\text { and air conditioning } \\
\text { (HVAC), security, } \\
\text { lighting and } \\
\text { sensing subsystems. }\end{array}$ & $\begin{array}{l}\text { We envision building systems to } \\
\text { exchange data across subsystems } \\
\text { as well as across various building } \\
\text { services in a programming } \\
\text { framework. Such information } \\
\text { exchange is mediated by timely } \\
\text { sensor information. }\end{array}$ & $\begin{array}{l}\text { A programming framework } \\
\text { comprised of machine learning } \\
\text { algorithms was developed } \\
\text { relying on a standard } \\
\text { information model for unified } \\
\text { and secure } \\
\text { application deployment }\end{array}$ & $\begin{array}{l}\text { Demonstrating new devices such } \\
\text { as thermostat called Genie, an } \\
\text { energy dashboard, and a } \\
\text { metadata models for building } \\
\text { portable applications for smart } \\
\text { buildings in this dissertation, we } \\
\text { continue to pursue building a } \\
\text { community of system builders for } \\
\text { the smart building environments. }\end{array}$ \\
\hline
\end{tabular}

Another attempt to integrate the data was performed by [123] in which semantic Construction Digital Twin was used in BIM which was apparently gained recognition. A smart monitoring technique for building fire prevention and disaster relief was also integrated into BIM hoping to reduce the fatalities and damages [30]. The results of this integration have shown a serious contribution to public safety. In another move of IoT 
integration in BIM, the role of BIM was improved in the transportation infrastructure [50]. The study aimed at developing more efficient and cost-effective techniques necessary to repair, advance, and expand the transportation infrastructure.

Moreover, [117] created diverse fields including BIM, information systems, Automation Systems, and IoT devices for the end-users. The end-users and other research groups benefited from such platforms by either consuming the data in their daily life or using the data for more advanced research.

Reference [9] designed and implemented a novel service management framework for IoT devices in the cloud computing system. The combination of the cloud computing environment and IoT has resulted in reducing the transmission and processing cost in the cloud and providing better services for processing and storing the real-time data generated from those IoT devices. Reference [55] significantly improved the systematic use of Information and Communication Technologies (ICT) tools and (BIM). The results were very promising and showed that such solutions could be key components of future digital toolkits for renovation design. Reference [109] used hybrid architecture for the integration of contextual information and time-series data.

This was another trial for implementing a new solution to the semantic data which was retained in its original format. This approach requires efficient relational databases storing time-series data and semantically described building contextual data. The most important part in this hybridization was to avoid the duplication of time-series data and to overcome some of the differences found in database schemas and database platforms.

Moreover, [140] created an IoT-based autonomous system for workers' safety in construction sites with real-time alarming, monitoring, and positioning strategies. The study extended the previous study of fire safety as noted earlier by [30].

In a very recent study, [119] recognized the top 10 technologies for indoor positioning on construction sites to demonstrate indoor positioning to enabling five significant applications that considerably enhance work efficiency and safety on construction sites. The last study performed by [37] in which metadata models and methods for Smart Buildings were proposed for using effective sensing data and (HVAC), security, lighting, and sensing subsystems. The study demonstrated new devices such as a thermostat called Genie, an energy dashboard, and a metadata models for building portable applications for smart buildings in this dissertation, we continue to pursue building a community of system builders for the smart building environments.

\section{Contribution}

The current review stressed the Semantic Web and relational databases to show a successful attempt to store cross-domain data. The procedure to achieve this goal was performed by three steps compromising to represent contextual information (sensor information and other soft building information) in RDF format, retaining data gathered by time-series data in the relational database, and mapping contextual information using sensor ID described in RDF.

The web and relational information approach are the most important procedure that could serve interlinking between various data sources. As such, a model was developed showing the effectiveness of storing time-series data in the relational model. The outcome shows the effectiveness of the query language resulted from integrating SPARQL and SQL. These developments were highly considered as the most promising methods to facilitate IoT deployment first and then to integrate the information in BIM and creating platforms and formats that were suitable for BIM-IoT integration. The other contribution of this study is to utilize standardized data formats and query language into specific domain data sources to extend project scope.

\section{Conclusions}

The information integration of smart industries is an important step toward better understanding the construction of the renovation of existing buildings. Despite developing 
smart technologies such as BIM and IoT, it was found that a single technology may face challenges that result in integrating two or technologies to deal with evolving challenges. It has been reported that BIM implementation requires the live data in addition to other physical data. For these consequences, models for BIM implementation should be developed and applied. The most important step is to the Service-Oriented-Architecture (SOA) whose features include service composition, service discovery, asset wrapping, model-driven implementation, loosely coupled, and platform-independent. SOA combines designing software and other services are combined aiming at providing large application functionalities through a communication protocol. The first item in developing a new IoTBIM integration is to reconsider the sematic information of BIM that was failed to display elements of indoor conditions. The second challenge is about the size of data stored in the system and the suitability of users to utilize this data. Several procedures were proposed to create open storage. BIM works very well for new developments; however, for the existing building, the role of BIM may become much harder. The current study contributes valuable information gathered from a long list of publications which are mainly during the last three years. The gathered information could benefit AEC, construction operation, monitoring, health and safety, and FM. It is also, this study sheds the light on the challenges and limitations of high-tech tools such as cameras and sensors. The goal of this study is to provide the best methodology to create a suitable database. The database created via BIM-IoT integration utilizes the Application Programming Interface (API) and relational data by creating new queries, language, semantic web technology, and hybridization. This study concludes that the possibility of prominent future research through which solving interoperability issues and cloud computing are heavily used. The digital revolution is the most important support of much potential BIM and IoT individually and under integration. This study also helps researchers to transform the traditional construction engineering to many advance concepts where visualization and industrial foundation cases are practiced. Updating static models towards real-time models is very important step which could result in developing new SOA patterns through which BIM can enable to update of the reading of IoT devices. Currently, this fusion is carried out by one-way interaction which could be developed to mimic the human-two-way approach by offering algorithms characterized by human cognitive buildings. Meanwhile, certain issues should be considered such as information consistency, traceability, and archiving. This is a high-tech approach that requires highly involving Cloud computations to better connect IoT devices throughout Internet infrastructure.

Author Contributions: Conceptualization, A.B.A.A. and N.A.H.; methodology, A.B.A.A.; writingoriginal draft preparation, A.B.A.A.; writing-review and editing, A.B.A.A.; supervision and reviewed the article, N.A.H.; Advice and support, A.H.A. and T.H.L. All authors have read and agreed to the published version of the manuscript.

Funding: This work was supported and partial funding by Research Management Centre, University Putra Malaysia.

Institutional Review Board Statement: Not Applicable.

Informed Consent Statement: Not Applicable.

Data Availability Statement: Not Applicable.

Acknowledgments: The authors would like to thank the Department of Civil Engineering, Faculty of Engineering, University Putra Malaysia, Serdang, Malaysia, for supporting this research paper.

Conflicts of Interest: The authors declare no conflict of interest. 


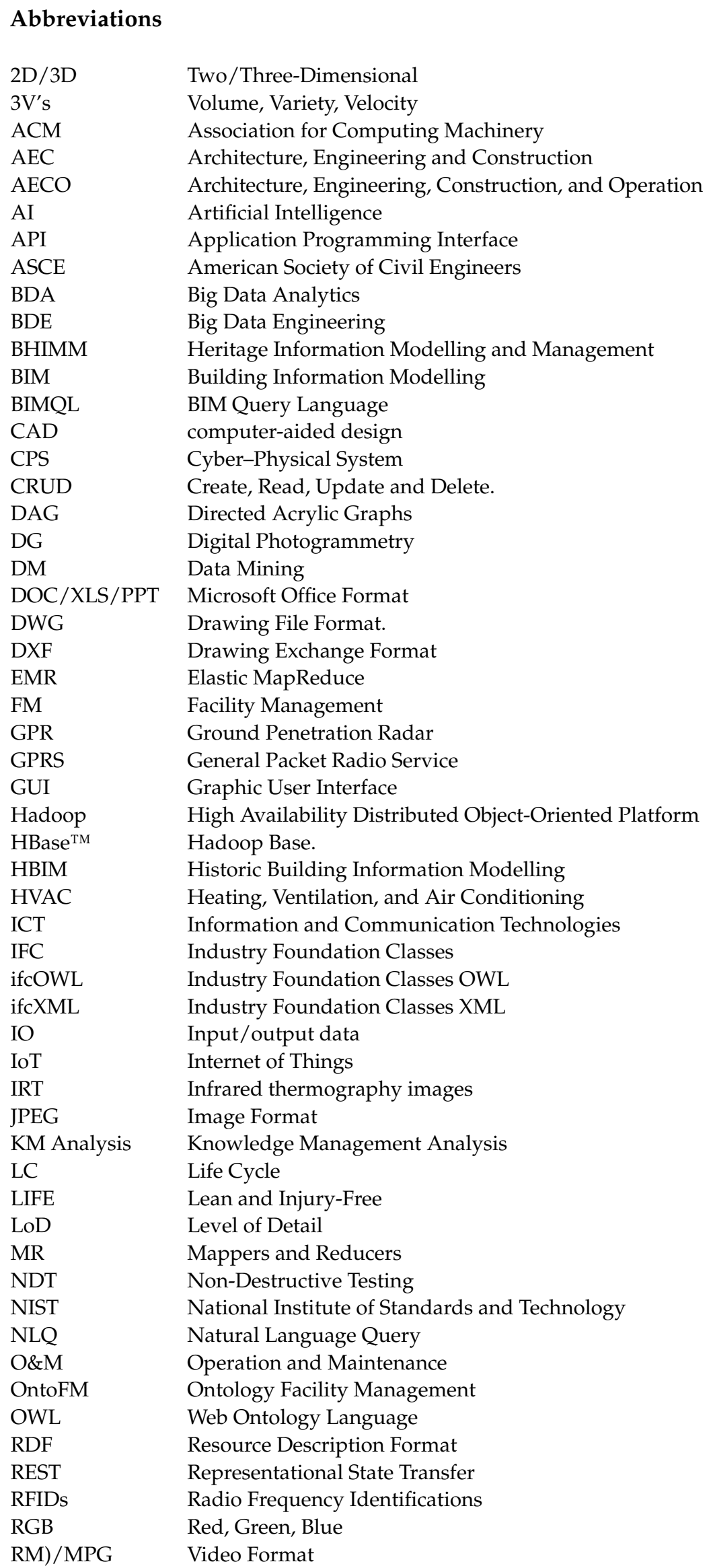




$\begin{array}{ll}\text { RVT (Revit) } & \text { Software for BIM } \\ \text { SAREF } & \text { Smart Appliances Reference ontology } \\ \text { SOA } & \text { Service-Oriented-Architecture } \\ \text { SPARQL } & \text { Query Language and Protocol. } \\ \text { SQL } & \text { Structured Query Language } \\ \text { SSN } & \text { Semantic Sensor Network } \\ \text { TLS } & \text { Terrestrial Laser Scanner } \\ \text { UAS } & \text { Unmanned Aerial Systems } \\ \text { XQuery } & \text { XML Query) }\end{array}$

\section{References}

1. Xu, X.; Mumford, T.; Zou, P.X. Life-cycle building information modelling (BIM) engaged framework for improving building energy performance. Energy Build. 2021, 231, 110496. [CrossRef]

2. Wang, C.; Cho, Y.K.; Kim, C. Automatic BIM component extraction from point clouds of existing buildings for sustainability applications. Autom. Constr. 2015, 56,1-13. [CrossRef]

3. Ansah, M.K.; Chen, X.; Yang, H.; Lu, L.; Lam, P.T. A review and outlook for integrated BIM application in green building assessment. Sustain. Cities Soc. 2019, 48, 101576. [CrossRef]

4. Lu, Y.; Wu, Z.; Chang, R.; Li, Y. Building Information Modeling (BIM) for green buildings: A critical review and future directions. Autom. Constr. 2017, 83, 134-148. [CrossRef]

5. Gao, J.; Zhong, X.; Cai, W.; Ren, H.; Huo, T.; Wang, X.; Mi, Z. Dilution effect of the building area on energy intensity in urban residential buildings. Nat. Commun. 2019, 10, 4944. [CrossRef]

6. Pourzolfaghar, Z.; McDonnell, P.; Helfert, M. Barriers to benefit from integration of building information with live data from IOT devices during the facility management phase. In Proceedings of the CITA BIM Gathering 2015, Dublin, Ireland, $23-24$ November 2017.

7. Gubbi, J.; Buyya, R.; Marusic, S.; Palaniswami, M. Internet of Things (IoT): A vision, architectural elements, and future directions. Future Gener. Comput. Syst. 2013, 29, 1645-1660. [CrossRef]

8. Čolaković, A.; Hadžialić, M. Internet of Things (IoT): A review of enabling technologies, challenges, and open research issues. Comput. Netw. 2018, 144, 17-39. [CrossRef]

9. Dehury, C.K.; Sahoo, P.K. Design and implementation of a novel service management framework for IoT devices in cloud. J. Syst. Softw. 2016, 119, 149-161. [CrossRef]

10. Tang, S.; Shelden, D.R.; Eastman, C.M.; Pishdad-Bozorgi, P.; Gao, X. A review of building information modeling (BIM) and the internet of things (IoT) devices integration: Present status and future trends. Autom. Constr. 2019, 101, 127-139. [CrossRef]

11. Teizer, J.; Wolf, M.; Golovina, O.; Perschewski, M.; Propach, M.; Neges, M.; König, M. Internet of Things (IoT) for integrating environmental and localization data in Building Information Modeling (BIM). In ISARC Proceedings of the International Symposium on Automation and Robotics in Construction (Vol. 34); Vilnius Gediminas Technical University: Vilnius, Lithuania, 2017.

12. Amano, K.; Lou, E.C.; Edwards, R. Integration of point cloud data and hyperspectral imaging as a data gathering methodology for refurbishment projects using Building Information Modelling (BIM). J. Facil. Manag. 2019, 17, 57-75. [CrossRef]

13. Ozturk, G.B. Interoperability in building information modeling for AECO/FM industry. Autom. Constr. 2020, 113, 103122. [CrossRef]

14. Akcamete, A.; Akinci, B.; Garrett, J.H., Jr. Motivation for computational support for updating building information models (BIMs). In Computing in Civil Engineering; ASCE: Reston, VA, USA, 2009; pp. 523-532.

15. Arayici, Y. Towards Building Information Modelling for Existing Structures. Structural Survey. Available online: http://usir. salford.ac.uk/id/eprint/12473/ (accessed on 27 February 2021).

16. Armesto, J.; Lubowiecka, I.; Ordóñez, C.; Rial, F.I. FEM modeling of structures based on close range digital photogrammetry. Autom. Constr. 2009, 18, 559-569. [CrossRef]

17. Klein, L.; Li, N.; Becerik-Gerber, B. Imaged-based verification of as-built documentation of operational buildings. Autom. Constr. 2012, 21, 161-171. [CrossRef]

18. ISO 22263:2008. Organization of Information About Construction Works_Framework for Management of Project Information, International Standard; ISO: Geneva, Switzerland, 2008.

19. Bilal, M.; Oyedele, L.O.; Qadir, J.; Munir, K.; Ajayi, S.O.; Akinade, O.O.; Pasha, M. Big Data in the construction industry: A review of present status, opportunities, and future trends. Adv. Eng. Inform. 2016, 30, 500-521. [CrossRef]

20. Zhao, X. A scientometric review of global BIM research: Analysis and visualization. Autom. Constr. 2017, 80, 37-47. [CrossRef]

21. Ding, K.; Shi, H.; Hui, J.; Liu, Y.; Zhu, B.; Zhang, F.; Cao, W. Smart steel bridge construction enabled by BIM and Internet of Things in industry 4.0: A framework. In Proceedings of the 2018 IEEE 15th International Conference on Networking, Sensing and Control (ICNSC), Zhuhai, China, 27-29 March 2018; IEEE: New York, NY, USA, 2018; pp. 1-5.

22. Fang, Y.; Cho, Y.K.; Durso, F.; Seo, J. Assessment of operator's situation awareness for smart operation of mobile cranes. Autom. Constr. 2018, 85, 65-75. [CrossRef]

23. Rahimian, F.P.; Seyedzadeh, S.; Oliver, S.; Rodriguez, S.; Dawood, N. On-demand monitoring of construction projects through a game-like hybrid application of BIM and machine learning. Autom. Constr. 2020, 110, 103012. [CrossRef] 
24. Zhong, R.Y.; Peng, Y.; Xue, F.; Fang, J.; Zou, W.; Luo, H.; Ng, S.T.; Lu, W.; Shen, G.Q.; Huang, G.Q. Prefabricated construction enabled by the Internet-of-Things. Autom. Constr. 2017, 76, 59-70. [CrossRef]

25. Xu, G.; Li, M.; Chen, C.H.; Wei, Y. Cloud asset-enabled integrated IoT platform for lean prefabricated construction. Autom. Constr. 2018, 93, 123-134. [CrossRef]

26. Li, C.Z.; Xue, F.; Li, X.; Hong, J.; Shen, G.Q. An Internet of Things-enabled BIM platform for on-site assembly services in prefabricated construction. Autom. Constr. 2018, 89, 146-161. [CrossRef]

27. Mostafa, S.; Kim, K.P.; Tam, V.W.; Rahnamayiezekavat, P. Exploring the status, benefits, barriers and opportunities of using BIM for advancing prefabrication practice. Int. J. Constr. Manag. 2020, 20, 146-156. [CrossRef]

28. Pärn, E.A.; Edwards, D.J. Conceptualising the FinDD API plug-in: A study of BIM-FM integration. Autom. Constr. 2017, 80, 11-21. [CrossRef]

29. Habibi, S. Micro-climatization and real-time digitalization effects on energy efficiency based on user behavior. Build. Environ. 2017, 114, 410-428. [CrossRef]

30. Cheng, M.Y.; Chiu, K.C.; Hsieh, Y.M.; Yang, I.T.; Chou, J.S.; Wu, Y.W. BIM integrated smart monitoring technique for building fire prevention and disaster relief. Autom. Constr. 2017, 84, 14-30. [CrossRef]

31. Dixit, M.K.; Venkatraj, V.; Ostadalimakhmalbaf, M.; Pariafsai, F.; Lavy, S. Integration of facility management and building information modeling (BIM). Facilities 2019, 37, 455-483. [CrossRef]

32. Kim, K.; Cho, Y.; Zhang, S. Integrating work sequences and temporary structures into safety planning: Automated scaffoldingrelated safety hazard identification and prevention in BIM. Autom. Constr. 2016, 70, 128-142. [CrossRef]

33. Eastman, C.M.; Teicholz, P.; Sacks, R.; Liston, K. Handbook BIM: A Guide to Building Information Modeling for Owners, Managers, Architects, Engineers, Contractors, and Fabricators; Wiley: Hoboken, NJ, USA, 2008.

34. Nawari, N.O.; Ravindran, S. Blockchain and building information modeling (BIM): Review and applications in post-disaster recovery. Buildings 2019, 9, 149. [CrossRef]

35. Shepherd, D. The BIM Management Handbook; Routledge: London, UK, 2019.

36. Bruno, N.; Roncella, R. HBIM for conservation: A new proposal for information modeling. Remote Sens. 2019, 11, 1751. [CrossRef]

37. Koh, J.B. Metadata Models and Methods for Smart Buildings. Ph.D. Thesis, University of California San Diego, San Diego, CA, USA, 2020.

38. Murphy, M.; McGovern, E.; Pavia, S. Historic building information modelling (HBIM). Struct. Surv. 2009, 27, 311-327. [CrossRef]

39. Bruno, S.; De Fino, M.; Fatiguso, F. Historic Building Information Modelling: Performance assessment for diagnosis-aided information modelling and management. Autom. Constr. 2018, 86, 256-276. [CrossRef]

40. Ciribini, A.L.C.; Ventura, S.M.; Paneroni, M. BIM methodology as an integrated approach to heritage conservation management. Wit Trans. Built Environ. 2015, 149, 265-276.

41. Ilter, D.; Ergen, E. BIM for building refurbishment and maintenance: Current status and research directions. Struct. Surv. 2015, 33, 228-256. [CrossRef]

42. Volk, R.; Stengel, J.; Schultmann, F. Building Information Modeling (BIM) for existing buildings—Literature review and future needs. Autom. Constr. 2014, 38, 109-127. [CrossRef]

43. Oreni, D.; Brumana, R.; Georgopoulos, A.; Cuca, B. HBIM for conservation and management of built heritage: Towards a library of vaults and wooden bean floors. ISPRS 2013, 5, W1. [CrossRef]

44. Sun, Z.; Xie, J.; Zhang, Y.; Cao, Y. As-Built BIM for a fifteenth-century Chinese brick structure at various LoDs. ISPRS Int. J. Geo-Inf. 2019, 8, 577. [CrossRef]

45. Fai, S.; Graham, K.; Duckworth, T.; Wood, N.; Attar, R. Building information modelling and heritage documentation. In Proceedings of the 23rd International Symposium, International Scientific Committee for Documentation of Cultural Heritage (CIPA), Prague, Czech Republic, 11-16 September 2011; pp. 12-16.

46. McArthur, J.J. A building information management (BIM) framework and supporting case study for existing building operations, maintenance and sustainability. Procedia Eng. 2015, 118, 1104-1111. [CrossRef]

47. Chiesa, G. ICT, Data and Design Issues. In Technological Paradigms and Digital Eras; Springer: Cham, Switzerland, 2020; pp. 1-38.

48. Cruz, I.F.; Xiao, H. Ontology driven data integration in heterogeneous networks. In Complex Systems in Knowledge-Based Environments: Theory, Models and Applications; Springer: Berlin/Heidelberg, Germany, 2009; pp. 75-98.

49. Hu, Z.Z.; Tian, P.L.; Li, S.W.; Zhang, J.P. BIM-based integrated delivery technologies for intelligent MEP management in the operation and maintenance phase. Adv. Eng. Softw. 2018, 115, 1-16. [CrossRef]

50. Costin, A.; Adibfar, A.; Hu, H.; Chen, S.S. Building Information Modeling (BIM) for transportation infrastructure-Literature review, applications, challenges, and recommendations. Autom. Constr. 2018, 94, 257-281. [CrossRef]

51. Zhai, Y.; Chen, K.; Zhou, J.X.; Cao, J.; Lyu, Z.; Jin, X.; Shen, G.Q.; Lu, W.; Huang, G.Q. An Internet of Things-enabled BIM platform for modular integrated construction: A case study in Hong Kong. Adv. Eng. Inform. 2019, 42, 100997. [CrossRef]

52. Hossain, M.A.; Yeoh, J.K.W. BIM for Existing Buildings: Potential Opportunities and Barriers. In IOP Conference Series: Materials Science and Engineering; IOP Publishing: Bristol, UK, 2018; Volume 371, p. 012051.

53. Motawa, I.; Almarshad, A. A knowledge-based BIM system for building maintenance. Autom. Constr. 2013, $29,173-182$. [CrossRef] 
54. Ghaffarianhoseini, A.; Tookey, J.; Ghaffarianhoseini, A.; Naismith, N.; Azhar, S.; Efimova, O.; Raahemifar, K. Building Information Modelling (BIM) uptake: Clear benefits, understanding its implementation, risks and challenges. Renew. Sustain. Energy Rev. 2017, 75, 1046-1053. [CrossRef]

55. Gimenez, L.; Robert, S.; Suard, F.; Zreik, K. Automatic reconstruction of 3D building models from scanned 2D floor plans. Autom. Constr. 2016, 63, 48-56. [CrossRef]

56. NBS. National BIM Report 2015; Royal Institute of British Architects: London, UK, 2015.

57. Lu, Q.; Lee, S. Image-based technologies for constructing as-is building information models for existing buildings. J. Comput. Civ. Eng. 2017, 31, 04017005. [CrossRef]

58. Laefer, D.F.; Truong-Hong, L. Toward automatic generation of 3D steel structures for building information modelling. Autom. Constr. 2017, 74, 66-77. [CrossRef]

59. Lucas, J.D. Managing the Facility with Lifecycle Information. J. Curr. Issues Media Telecommun. 2015, 7, 13-36.

60. Teicholz, E. Bridging the AEC technology gap. IFMA Facil. Manag. J. 2004, 587, 588.

61. IFMA. Exploring the Current Trends and Future Outlook for Facility Management; Facility Management Forecast 2011; The International Facility Management Association: Houston, TX, USA, 2011; ISBN 1-883176-84-0.

62. Saberi, S.; Kouhizadeh, M.; Sarkis, J.; Shen, L. Blockchain technology and its relationships to sustainable supply chain management. Int. J. Prod. Res. 2019, 57, 2117-2135. [CrossRef]

63. Ma, Z.; Cooper, P.; Daly, D.; Ledo, L. Existing building retrofits: Methodology and state-of-the-art. Energy Build. 2012, 55, 889-902. [CrossRef]

64. Shaikh, P.H.; Shaikh, F.; Sahito, A.A.; Uqaili, M.A.; Umrani, Z. An Overview of the Challenges for Cost-Effective and EnergyEfficient Retrofits of the Existing Building Stock. In Cost-Effective Energy Efficient Building Retrofitting; Woodhead Publishing: Swaston, UK, 2017; pp. 257-278.

65. Asadi, E.; Da Silva, M.G.; Antunes, C.H.; Dias, L. Multi-objective optimization for building retrofit strategies: A model and an application. Energy Build. 2012, 44, 81-87. [CrossRef]

66. Huang, Z.; Ge, J.; Zhao, K.; Shen, J. Post-evaluation of energy consumption of the green retrofit building. Energy Procedia 2019, 158, 3608-3613. [CrossRef]

67. Salvalai, G.; Sesana, M.M.; Iannaccone, G. Deep renovation of multi-storey multi-owner existing residential buildings: A pilot case study in Italy. Energy Build. 2017, 148, 23-36. [CrossRef]

68. Xiaonuan, S.; SiuYu, S.L. Existing buildings' operation and maintenance: Renovation project of Chow Yei Ching Building at the University of Hong Kong. Int. J. Low-Carbon Technol. 2014, 10, 393-404. [CrossRef]

69. Pärn, E.A.; Edwards, D.J.; Sing, M.C. The building information modelling trajectory in facilities management: A review. Autom. Constr. 2017, 75, 45-55. [CrossRef]

70. Kassem, M.; Kelly, G.; Dawood, N.; Serginson, M.; Lockley, S. BIM in facilities management applications: A case study of a large university complex. Built Environ. Proj. Asset. Manag. 2015, 5, 261-277. [CrossRef]

71. Bortoluzzi, B.; Efremov, I.; Medina, C.; Sobieraj, D.; McArthur, J.J. Automating the creation of building information models for existing buildings. Autom. Constr. 2019, 105, 102838. [CrossRef]

72. Dixit, M.K.; Venkatraj, V. Integrating facility management functions in building information modeling (BIM): A review of key issues and challenges. In Proceedings of the International Research Conference (IRC) 2017: Shaping Tomorrow's Built Environment Conference Proceedings, Salford, UK, 11-12 September 2017; pp. 597-608.

73. Carli, R.; Dotoli, M.; Pellegrino, R.; Ranieri, L. Using multi-objective optimization for the integrated energy efficiency improvement of a smart city public buildings' portfolio. In Proceedings of the 2015 IEEE International Conference on Automation Science and Engineering (CASE), Gothenburg, Sweden, 24-28 August 2015; pp. 21-26.

74. Peng, Y.; Lin, J.R.; Zhang, J.P.; Hu, Z.Z. A hybrid data mining approach on BIM-based building operation and maintenance. Build. Environ. 2017, 126, 483-495. [CrossRef]

75. Quattrini, R.; Pierdicca, R.; Morbidoni, C. Knowledge-based data enrichment for HBIM: Exploring high-quality models using the semantic-web. J. Cult. Herit. 2017, 28, 129-139. [CrossRef]

76. Wanner, E. On Remembering, Forgetting, and Understanding Sentences: A Study of the Deep Structure Hypothesis; Walter de Gruyter GmbH Co KG: Berlin, Germany, 2019; Volume 170.

77. Pourzolfaghar, Z.; Helfert, M. Integration of buildings information with live data from IoT devices. In Connected Environments for the Internet of Things; Springer: Cham, Switzerland, 2017; pp. 169-185.

78. Dexeus, C.R. The deepening effects of the digital revolution. In The Future of Tourism; Springer: Cham, Switzerland, 2019; pp. 43-69.

79. Eadie, R.; Browne, M.; Odeyinka, H.; McKeown, C.; McNiff, S. BIM implementation throughout the UK construction project lifecycle: An analysis. Autom. Constr. 2013, 36, 145-151. [CrossRef]

80. Jiao, Y.; Zhang, S.; Li, Y.; Wang, Y.; Yang, B.; Wang, L. An augmented Mapreduce framework for building information modeling applications. In Proceedings of the 2014 IEEE 18th International Conference on Computer Supported Cooperative Work in Design (CSCWD), Hsinchu, Taiwan, 21-23 May 2014; IEEE: New York, NY, USA, 2014; pp. 283-288.

81. Lin, J.R.; Hu, Z.Z.; Zhang, J.P.; Yu, F.Q. A Natural-Language-Based Approach to Intelligent Data Retrieval and Representation for Cloud BIM. Comput. Aided Civ. Infrastruct. Eng. 2016, 31, 18-33. [CrossRef] 
82. Zheng, R.; Jiang, J.; Hao, X.; Ren, W.; Xiong, F.; Ren, Y. bcBIM: A blockchain-based big data model for BIM modification audit and provenance in mobile cloud. Math. Probl. Eng. 2019, 2019. [CrossRef]

83. Hofmann, E. Big data and supply chain decisions: The impact of volume, variety and velocity properties on the bullwhip effect. Int. J. Prod. Res. 2017, 55, 5108-5126. [CrossRef]

84. Provost, F.; Fawcett, T. Data Science for Business: What You Need to Know about Data Mining and Data-Analytic Thinking; O'Reilly Media, Inc.: Newton, MA, USA, 2013.

85. Ray, P.D. Pervasive, Domain and Situational-Aware, Adaptive, Automated, and Coordinated Big Data Analysis, Contextual Learning and Predictive Control of Business and Operational Risks and Security. U.S. Patent No. 10,210,470, 19 February 2019.

86. Matsunaga, F.T.; Brancher, J.D.; Busto, R.M. Data mining techniques and tasks for multidisciplinary applications: A systematic review. ReABTIC 2015, 1. [CrossRef]

87. Dean, J.; Ghemawat, S. MapReduce: Simplified data processing on large clusters. Commun. ACM 2008, 51, 107-113. [CrossRef]

88. Wang, Q.; Lee, B.; Murray, N.; Qiao, Y. MR-IoT: An information centric MapReduce framework for IoT. In Proceedings of the 2018 15th IEEE Annual Consumer Communications \& Networking Conference (CCNC), Las Vegas, NV, USA, 12-15 January 2018; pp. 1-6.

89. Qadir, J.; Ahad, N.; Mushtaq, E.; Bilal, M. SDNs, clouds, and big data: New opportunities. In Proceedings of the 2014 12th International Conference on Frontiers of Information Technology, Islamabad, Pakistan, 17-19 December 2014 ; pp. $28-33$.

90. Agneeswaran, V.S. Big Data Analytics beyond Hadoop: Real-Time Applications with Storm, Spark, and More Hadoop Alternatives; FT Press: Upper Saddle River, NJ, USA, 2014.

91. Watson, H.J. Update tutorial: Big Data analytics: Concepts, technology, and applications. Commun. Assoc. Inf. Syst. 2019, 44, 365-379.

92. Lu, J.; Chen, Y.; Herodotou, H.; Babu, S. Speedup your analytics: Automatic parameter tuning for databases and big data systems. Proc. Vldb Endow. 2019, 12, 1970-1973. [CrossRef]

93. Chen, H.; Chang, P.; Hu, Z.; Fu, H.; Yan, L. A Spark-based Ant Lion Algorithm for Parameters Optimization of Random Forest in Credit Classifi.cation. In Proceedings of the 2019 IEEE 3rd Information Technology, Networking, Electronic and Automation Control Conference (ITNEC), Chengdu, China, 15-17 March 2019; pp. 992-996.

94. Singh, D.; Reddy, C.K. A survey on platforms for big data analytics. J. Big Data 2015, 2, 8. [CrossRef] [PubMed]

95. Karau, H.; Konwinski, A.; Wendell, P.; Zaharia, M. Learning Spark: Lightning-Fast Big Data Analysis; O’Reilly Media, Inc.: Newton, MA, USA, 2015.

96. Garofalo, M.; Botta, A.; Ventre, G. Astrophysics and big data: Challenges, methods, and tools. Proc. Int. Astron. Union 2016, 12, 345-348. [CrossRef]

97. Corry, E.; O’Donnell, J.; Curry, E.; Coakley, D.; Pauwels, P.; Keane, M. Using semantic web technologies to access soft AEC data. Adv. Eng. Inform. 2014, 28, 370-380. [CrossRef]

98. Kazmi, A.H.; O'grady, M.J.; Delaney, D.T.; Ruzzelli, A.G.; O’hare, G.M. A review of wireless-sensor-network-enabled building energy management systems. ACM Trans. Sens. Netw. (TOSN) 2014, 10, 66. [CrossRef]

99. Woo, J.H.; Peterson, M.A.; Gleason, B. Developing a virtual campus model in an interactive game-engine environment for building energy benchmarking. J. Comput. Civ. Eng. 2016, 30, C4016005. [CrossRef]

100. Lingappa, P.R. Master Applet for Secure Remote Payment Processing. U.S. Patent No. 10,592,899, 17 March 2020.

101. Abu-Tair, M.; Djahel, S.; Perry, P.; Scotney, B.; Zia, U.; Carracedo, J.M.; Sajjad, A. Towards Secure and Privacy-Preserving IoT Enabled Smart Home: Architecture and Experimental Study. Sensors 2020, 20, 6131. [CrossRef] [PubMed]

102. Motamedi, A.; Hammad, A.; Asen, Y. Knowledge-assisted BIM-based visual analytics for failure root cause detection in facilities management. Autom. Constr. 2014, 43, 73-83. [CrossRef]

103. Singh, G.; Solanki, A. An algorithm to transform natural language into SQL queries for relational databases. Selforganizology 2016, 3, 100-116.

104. Mazairac, W.; Beetz, J. BIMQL-An open query language for building information models. Adv. Eng. Inform. 2013, 27, 444-456. [CrossRef]

105. Schreiber, G.; Akkermans, H.; Anjewierden, A.; Shadbolt, N.R.; de Hoog, R.; Van de Velde, W.; Wielinga, B.J. Knowledge Engineering and Management: The CommonKADS Methodology; MIT Press: Cambridge, MA, USA, 2000.

106. Chen, L.; Shadbolt, N.R.; Goble, C.A. A semantic web-based approach to knowledge management for grid applications. IEEE Trans. Knowl. Data Eng. 2006, 19, 283-296. [CrossRef]

107. Dibley, M.; Li, H.; Rezgui, Y.; Miles, J. An ontology framework for intelligent sensor-based building monitoring. Autom. Constr. 2012, 28, 1-14. [CrossRef]

108. Curry, E.; O’Donnell, J.; Corry, E.; Hasan, S.; Keane, M.; O’Riain, S. Linking building data in the cloud: Integrating cross-domain building data using linked data. Adv. Eng. Inform. 2013, 27, 206-219. [CrossRef]

109. Hu, S.; Corry, E.; Curry, E.; Turner, W.J.; O’Donnell, J. Building performance optimisation: A hybrid architecture for the integration of contextual information and time-series data. Autom. Constr. 2016, 70, 51-61. [CrossRef]

110. Fedushko, S.; Ustyianovych, T. Operational Intelligence Software Concepts for Continuous Healthcare Monitoring and Consolidated Data Storage Ecosystem. In International Conference on Computer Science, Engineering and Education Applications; Springer: Cham, Switzerland, 2020; pp. 545-557. 
111. Fedushko, S.; Ustyianovych, T.; Gregus, M. Real-time high-load infrastructure transaction status output prediction using operational intelligence and big data technologies. Electronics 2020, 9, 668. [CrossRef]

112. Ogasawara, G.H.; Tso, M.M. Hybrid Data Management System and Method for Managing Large, Varying Datasets. U.S. Patent No. 9,396,290, 19 July 2016.

113. McGlinn, K.; Yuce, B.; Wicaksono, H.; Howell, S.; Rezgui, Y. Usability evaluation of a web-based tool for supporting holistic building energy management. Autom. Constr. 2017, 84, 154-165. [CrossRef]

114. Li, J.; Kassem, M.; Ciribini, A.L.C.; Bolpagni, M. A proposed approach integrating DLT, BIM, IOT and smart contracts: Demonstration using a simulated installation task. In International Conference on Smart Infrastructure and Construction 2019 (ICSIC) Driving Data-Informed Decision-Making; ICE Publishing: London, UK, 2019; pp. 275-282.

115. Sacks, R.; Eastman, C.; Lee, G.; Teicholz, P. BIM Handbook: A Guide to Building Information Modeling for Owners, Designers, Engineers, Contractors, and Facility Managers; John Wiley Sons: Hoboken, NJ, USA, 2018.

116. Dallasega, P.; Rauch, E.; Linder, C. Industry 4.0 as an enabler of proximity for construction supply chains: A systematic literature review. Comput. Ind. 2018, 99, 205-225. [CrossRef]

117. Dave, B.; Buda, A.; Nurminen, A.; Främling, K. A framework for integrating BIM and IoT through open standards. Autom. Constr. 2018, 95, 35-45. [CrossRef]

118. Hosseini, S.M.; Carli, R.; Dotoli, M. Robust optimal energy management of a residential microgrid under uncertainties on demand and renewable power generation. IEEE Trans. Autom. Sci. Eng. 2020, 1-20. [CrossRef]

119. Li, C.T.; Cheng, J.C.; Chen, K. Top 10 technologies for indoor positioning on construction sites. Autom. Constr. 2020, 118, 103309. [CrossRef]

120. Blaauwbroek, N.; Nguyen, P.H.; Konsman, M.J.; Shi, H.; Kamphuis, R.I.; Kling, W.L. Decentralized resource allocation and load scheduling for multicommodity smart energy systems. IEEE Trans. Sustain. Energy 2015, 6, 1506-1514. [CrossRef]

121. Maskuriy, R.; Selamat, A.; Ali, K.N.; Maresova, P.; Krejcar, O. Industry 4.0 for the construction industry-How ready is the industry? Appl. Sci. 2019, 9, 2819. [CrossRef]

122. Boje, C.; Guerriero, A.; Kubicki, S.; Rezgui, Y. Towards a semantic Construction Digital Twin: Directions for future research. Autom. Constr. 2020, 114, 103179. [CrossRef]

123. Lavy, S.; Jawadekar, S. A case study of using BIM and COBie for facility management. Int. J. Facil. Manag. 2014, 5, 109458840.

124. Koch, C.; Hansen, G.K.; Jacobsen, K. Missed opportunities: Two case studies of digitalization of FM in hospitals. Facilities 2019, 37, 381-394. [CrossRef]

125. Shirowzhan, S.; Sepasgozar, S.M.; Edwards, D.J.; Li, H.; Wang, C. BIM compatibility and its differentiation with interoperability challenges as an innovation factor. Autom. Constr. 2020, 112, 103086. [CrossRef]

126. Son, H.; Kim, C.; Turkan, Y. Scan-to-BIM-an overview of the current state of the art and a look ahead. In ISARC. Proceedings of the International Symposium on Automation and Robotics in Construction; IAARC Publications: London, UK, 2015; Volume 32, p. 1.

127. Hess, M.; Petrovic, V.; Yeager, M.; Kuester, F. Terrestrial laser scanning for the comprehensive structural health assessment of the Baptistery di San Giovanni in Florence, Italy: An integrative methodology for repeatable data acquisition, visualization and analysis. Struct. Infrastruct. Eng. 2018, 14, 247-263. [CrossRef]

128. Fricker, P.; Sandau, R.; Walker, A.S. Development of an airborne digital sensor for photogrammetric and remote sensing applications. In Proceedings of the ASPRS Annual Conference, Washington, DC, USA, 21-26 May 2000.

129. Dai, F.; Feng, Y.; Hough, R. Photogrammetric error sources and impacts on modeling and surveying in construction engineering applications. Vis. Eng. 2014, 2, 1-14. [CrossRef]

130. Tang, P.; Huber, D.; Akinci, B.; Lipman, R.; Lytle, A. Automatic reconstruction of as-built building information models from laser-scanned point clouds: A review of related techniques. Autom. Constr. 2010, 19, 829-843. [CrossRef]

131. Hernandez-Marin, S.; Wallace, A.M.; Gibson, G.J. Bayesian analysis of lidar signals with multiple returns. IEEE Trans. Pattern Anal. Mach. Intell. 2007, 29, 2170-2180. [CrossRef] [PubMed]

132. Maser, K.R. Condition assessment of transportation infrastructure using ground-penetrating radar. J. Infrastruct. Syst. 2007, 2, 94-101. [CrossRef]

133. Maierhofer, C. Nondestructive evaluation of concrete infrastructure with ground penetrating radar. J. Mater. Civ. Eng. 2003, 15, 287-297. [CrossRef]

134. Solla, M.; Gonçalves, L.M.S.; Gonçalves, G.; Francisco, C.; Puente, I.; Providência, P.; Gaspar, F.; Rodrigues, H. A Building Information Modeling Approach to Integrate Geomatic Data for the Documentation and Preservation of Cultural Heritage. Remote Sens. 2020, 12, 4028. [CrossRef]

135. Isikdag, U. Enhanced building information models. In Enhanced Building Information Models: Using IoT Services and Integration Patterns; Springer International Publishing : New York, NY, USA, 2015; pp. 13-24. [CrossRef]

136. Thu Nguyen, Integration of BIM and IoT to Improve Building Performance for OCCUPANTS' perspectives. Master's Thesis, KTH Royal Institute of Technology, Stockholm, Sweden, 2016.

137. Rowley, J. The wisdom hierarchy: Representations of the DIKW hierarchy. J. Inf. Sci. 2007, 33, 163-180. [CrossRef]

138. Ufuk-Gökçe, H.; Umut-Gökçe, K. Integrated system platform for energy efficient building operations. J. Comput. Civ. Eng. 2014, 28, 05014005. [CrossRef]

139. Pishdad-Bozorgi, P.; Gao, X.; Eastman, C.; Self, A.P. Planning and developing facility management-enabled building information model (FM-enabled BIM). Autom. Constr. 2018, 87, 22-38. [CrossRef] 
140. Khalid, M.U.; Bashir, M.K.; Newport, D. Development of a building information modelling (BIM)-based real-time data integration system using a building management system (BMS). In Building Information Modelling, Building Performance, Design and Smart Construction; Springer: Cham, Switzerland, 2017; pp. 93-104.

141. Desogus, G.; Quaquero, E.; Sanna, A.; Gatto, G.; Tagliabue, L.C.; Rinaldi, S.; Ciribini, A.L.C.; Di Giuda, G.; Villa, V. Preliminary performance monitoring plan for energy retrofit: A cognitive building: The "Mandolesi Pavillon" at the University of Cagliari. In Proceedings of the 2017 AEIT International Annual Conference, Cagliari, Italy, 20-22 September 2017; pp. 1-6.

142. Hefnawy, A.; Bouras, A.; Cherifi, C. IoT for smart city services: Lifecycle approach. In Proceedings of the International Conference on Internet of things and Cloud Computing, Cambridge, UK, 23 February-22 March 2016; pp. 1-9.

143. Shabanzadeh, M.; Sheikh-El-Eslami, M.K.; Haghifam, M.R. A medium-term coalition-forming model of heterogeneous DERs for a commercial virtual power plant. Appl. Energy 2016, 169, 663-681. [CrossRef]

144. Kanan, R.; Elhassan, O.; Bensalem, R. An IoT-based autonomous system for workers' safety in construction sites with real-time alarming, monitoring, and positioning strategies. Autom. Constr. 2018, 88, 73-86. [CrossRef] 